\title{
Los archivos, la intimidad de las personas y los secretos de Estado
}

\author{
Antonio NiÑo y Carlos SAnZ \\ Universidad Complutense de Madrid \\ anino@ghis.ucm.es y carlos.sanz@ghis.ucm.es
}

Recibido: $15 / 06 / 2012$

Aceptado: 10/07/2012

\begin{abstract}
RESUMEN
El artículo repasa la normativa española sobre el derecho de acceso a la documentación pública, su aplicación en los archivos y las consecuencias para la investigación histórica. Aunque las primeras leyes promulgadas en el periodo democrático fueron muy aperturistas, el desarrollo de la legislación sobre protección de datos personales ha restringido de forma severa el acceso a la documentación histórica. La indefinición y las contradicciones de las sucesivas normas, junto con las malas prácticas persistentes en la administración de los archivos públicos, están ocasionando trabas injustificadas para acceder a la documentación. A estos problemas se ha sumado recientemente la decisión gubernativa de extender la protección que proporcionada la Ley de Secretos Oficiales a múltiples materias relacionadas con la política exterior. Con todo ello, los historiadores encuentran graves dificultades para estudiar los periodos más recientes de la historia española.
\end{abstract}

Palabras clave: Archivos históricos, Derecho de acceso, Secretos de Estado, Historiografía.

\section{Archives, Privacy and State Secrets}

\begin{abstract}
This paper reviews the laws and norms regulating access to public documents in Spain, as well as their actual implementation in archival institutions and their consequences for historical research. Despite the liberal character of the early laws enacted in the democratic period, the publication of subsequent privacy regulations has severely curtailed access to historical documents. The vagueness and contradictions of the relevant norms, combined with the negligence typical of Spanish public archives, are posing greater burdens in researchers' access to archival material. A situation worsened by the recent governmental decision to extend the scope of the State Secrets Act (Ley de Secretos Oficiales) to cover a number of issues relating to foreign policy. As a result, historians are finding more and more difficult the study of recent Spanish History.
\end{abstract}

Key words: Historical Archives, Access to Information, State Secrets, Historiography.

Sumario: 1. La protección de la intimidad de las personas como excusa para impedir el acceso a la documentación histórica. 2. Las malas prácticas en la aplicación de las normas que limitan la libertad de acceso a la documentación. 3. Los secretos de Estado y las barreras a la investigación. 4. Conclusiones. 
En los últimos años se vienen repitiendo las quejas y denuncias por parte de investigadores que ven restringido el derecho de acceso a los fondos documentales custodiados en archivos públicos españoles. Declaraciones de asociaciones de historiadores ${ }^{1}$, acuerdos adoptados en congresos profesionales ${ }^{2}$, artículos en revistas científicas ${ }^{3}$ y un sinfín de recursos contra resoluciones administrativas coindicen en denunciar un retroceso en la aplicación de las normas que regulan el libre acceso al patrimonio histórico documental. Nadie sería capaz de hacer el inventario de cuántos proyectos de investigación han sido frustrados -muchos financiados con recursos públicos-, cuántas tesis doctorales imposibilitadas, qué cantidad de investigaciones abortadas, y de qué manera se ha limitado el conocimiento de nuestro pasado reciente por las crecientes dificultades de acceso a la documentación de archivo ${ }^{4}$.

Algunas decisiones recientes vuelven a poner de actualidad este tema. Una es la publicación del Real Decreto 1708/2011, de 18 de noviembre, por el que se establece el Sistema Español de Archivos y se regula el Sistema de Archivos de la Administración General del Estado y de sus Organismos Públicos y su régimen de acceso (en adelante RDSEA), que viene a complicar aún más el problema del acceso a los archivos públicos. Otra es la decisión por Consejo de Ministros de declarar secretas la práctica totalidad de las materias tratadas en la documentación del Ministerio de Asuntos Exteriores y Cooperación. Ambas normas han tenido graves consecuencias sobre el trabajo de los investigadores, y por ello merecen un detallado análisis desde el punto de vista de la investigación histórica. Eso es lo que nos proponemos hacer en este artículo.

Lo más sorprendente es que este giro involucionista viene a contradecir el espíritu aperturista -nunca mejor utilizado este término-que inspiraron las primeras leyes de la democracia sobre la materia. La primera y más importante de ellas, la Ley 16/1985 de Patrimonio Histórico Español (en adelante LPHE), establecía el principio general de libre acceso a los fondos de los archivos que custodiaran documentación histórica, y además declaraba en el artículo 2.1, que «son deberes y atribuciones esenciales de la Administración del Estado [...] fomentar y tutelar el acceso de todos los ciudadanos a los bienes comprendidos en él [Patrimonio Histórico Español]». Por su parte, la Ley de 30/1992 de Régimen Jurídico de las Administraciones Públicas y Procedimiento

1 Véase el Manifiesto de la Junta Directiva de la Asociación de Historia Contemporánea, de 19 de febrero de 2011: "El acceso a los archivos y la investigación histórica": http://www.ahistcon.org/docs/Manifiesto\%20 archivos.pdf [consultado el 1/07/2012]

2 Véase el Manifiesto de la Asamblea de la Asociación de Historia Contemporánea celebrada en Santiago de Compostela el día 22 de septiembre de 2004: http://www.ahistcon.org/docs/comunicado\%20archivos 2004. pdf [consultado el 1/07/2012]

3 Desde el punto de vista de los investigadores, véase José Ramón URQUIJO GOITIA, “Archivos e historia contemporánea", Ayer, 61 (2006), pp. 311-325; Antonio NIÑO, "La acción preventiva y el acceso a los archivos históricos", Cuadernos de Historia Contemporánea, 27 (2005), 299-307, y Carme MOLINERO, "El acceso a los archivos y la investigación histórica", Ayer, 81 (2011), 285-297.

4 Baste un ejemplo: el funcionamiento del aparato policial bajo el franquismo no ha podido ser investigado, a pesar de contar con un proyecto financiado por el Ministerio de la Presidencia, por las trabas para acceder a los fondos del Ministerio del Interior. Véase Julio ARÓSTEGUI, Jorge MARCO y Gutmaro GÓMEZ BRAVO, "Visiones, enfoques y evidencias: la Cátedra de Memoria Histórica del Siglo XX", Historiografias, 3 (enero-junio, 2012): pp. 83. http://www.unizar.es/historiografias/historiografias/numeros $/ 3 / \mathrm{memorias} . \mathrm{pdf}$ [consultado el 1/07/2012] 
Administrativo Común (en adelante LRJAPPAC), también establecía el libre acceso a la documentación de los archivos de gestión, siempre que los expedientes estuvieran concluidos y con determinadas condiciones. En ambos casos no se establecían plazos temporales y el principio de libre acceso sólo se limitaba en casos excepcionales y expresamente tasados por la ley. Fue un gran avance de la democracia reconocer el derecho de los ciudadanos a acceder a la documentación pública, hasta entonces limitado a la discrecionalidad administrativa. Desgraciadamente, como veremos más adelante, las excepciones han acabado convirtiéndose en la norma, y el principio general de libre acceso ha sido relegado progresivamente al olvido.

Aquella liberalidad en el acceso a la documentación histórica que inspiraba las leyes de 1985 y 1992 ha quedado anulada por las restricciones que, poco a poco, se han ido poniendo al principio de libre acceso. Las limitaciones proceden en esencia de dos frentes. Uno de ellos es la regulación extremadamente rigurosa de la protección de la intimidad de las personas, establecida por la Ley Orgánica 15/1999 de Protección de Datos de Carácter Personal (en adelante LOPDP) y sus desarrollos. El otro frente es la extensión desmesurada de lo que se considera secreto oficial, un tipo de información protegido por una norma franquista y preconstitucional, la Ley 9/1968 sobre Secretos Oficiales, modificada por la ley 48/1978 (en adelante LSO). Veremos cómo se ha producido ese ataque al derecho de acceso desde estos dos flancos, y cómo las últimas disposiciones que se han tomado para resolver las contradicciones e inconsecuencias creadas por las sucesivas leyes han agravado aún más la situación para los investigadores ${ }^{5}$. La situación se ha deteriorado tan gravemente, desde el punto de vista de las facilidades para la consulta de la documentación de archivo, que muchos pensamos que es el momento de solicitar una modificación a fondo de la regulación de ese derecho. El lector perdonará esta incursión en un debate jurídico que puede resultar abstruso, pero se trata de hacer luz sobre una legislación cuya aplicación está teniendo graves consecuencias sobre la investigación histórica.

5 Los especialistas en derecho administrativo han publicado una gran cantidad de análisis sobre las contradicciones de la actual regulación del acceso a la documentación pública; algunos de ellos son: Severiano FERNANDEZ RAMOS, El derecho de acceso a los documentos administrativos, Madrid, Marcial Pons, 1997, y del mismo autor, «El derecho de acceso a los documentos públicos en el marco del sistema archivístico», en VVAA, El derecho de acceso de los ciudadanos a la información contenida en los archivos, Toledo, Junta de Comunidades de Castilla-La Mancha, 2001. Los archiveros también han destacado la heterogeneidad y las contradicciones del actual marco normativo sobre el derecho de acceso a los archivos públicos. Son de especial interés los análisis de Daniel OCAÑA LACAL, «Ignorancia, ilegalidad y otros males: panorámica del derecho de acceso a los archivos públicos en España», en Boletín de ANABAD, 3-4 (1999), pp. 173-210; LASSO BALLESTEROS Angel, «El acceso a los documentos administrativos: derecho, laberinto y decepción», en Boletín ACAL, 33 (tercer trimestre 1999), pp. 22-27. Daniel OCAÑA LACAL; «El archivero y la aplicación de la legislación sobre acceso», en El derecho de acceso de los ciudadanos a la información contenida en los archivos, Toledo, Junta de Comunidades de Castilla-La Mancha, 2001, Alberto CARRILLO-LINARES; «Reflexiones y propuestas para una correcta interpretación de la Ley 16/1985, del Patrimonio Histórico Español, sobre el artículo 57 y el acceso a los archivos», Boletín de ANABAD, 3 (2005), pp. 11-48; y el último artículo de Daniel OCAÑA LACAL, «Ser o no ser: el archivero entre el derecho de acceso y la protección de la información”, Tabula, 15 (2012), pp. 149-184. 


\section{La protección de la intimidad de las personas como excusa para impedir el acceso a la documentación histórica}

Trataremos en primer lugar la ofensiva contra la libertad de investigación procedente de la legislación sobre protección de datos de carácter personal. Los derechos en cuestión arrancan de la propia Constitución Española de 19786. Para desarrollar esos preceptos se promulgó una primera norma, la Ley Orgánica 1/1982, de Protección Civil del Derecho al Honor, a la Intimidad Personal y Familiar y a la Propia Imagen (LOPHI). Esta ley, como se dice en su preámbulo, estaba concebida para establecer un límite al ejercicio de las libertades de expresión, no al derecho de información o de acceso al patrimonio documental. De forma general, la ley prohíbe «la difusión» de todo lo que atente contra la reputación y buen nombre de una persona o familia. En el art.7.4 se dice que tendrán la consideración de intromisiones ilegítimas en el ámbito de protección delimitado por esta ley: «La revelación de datos privados de una persona o familia conocidos a través de la actividad profesional $u$ oficial de quien los revela». Está claro que esta ley regulaba la difusión y revelación de ciertos datos, pero no impedía el acceso a esos datos, menos aún a los contenidos en los documentos de los archivos históricos. Los legisladores, con buen tino, pretendían evitar la divulgación pública de informaciones que pudieran afectar a la intimidad de las personas, no limitar el derecho a la información.

Posteriormente, la LPHE 15/1985 establecía excepciones al principio general del libre acceso a la documentación de los archivos, entre ellas la que contuviera «datos personales de carácter policial, procesal, clínico o de cualquier otra índole que puedan afectar a la seguridad de las personas», así como los «datos personales... que puedan afectar... a su honor, a la intimidad de su vida privada y familiar y a su propia imagen» (artículo 57.1.c). En estos casos establecía plazos temporales para permitir el acceso: veinticinco años desde el fallecimiento de los afectados o cincuenta años desde la fecha de creación de los documentos solicitados. Obsérvese que, en su tenor literal, la ley se refiere a documentos que contengan datos..., no a fondos documentales completos, y a aquellos que contengan no cualquier dato personal, sino el tipo de datos personales expresamente enumerados. Pero al no especificar la propia ley qué debía entenderse por honor, intimidad e imagen de las personas, se abría un amplio margen a la arbitrariedad e inseguridad jurídica, pues se dejaba a la estimación subjetiva de la Administración la facultad de resolver esas ambigüedades. ¿Quién define qué debe entenderse por honor o intimidad? ¿Y cómo decidir si tales o cuales datos ponen en peligro tan preciados bienes? Los juristas han encontrado en estos temas un filón para sutiles y bizantinas disquisiciones, pero en la práctica son los funcionarios

\footnotetext{
6 En el art. 18.1 la Constitución dispone: "Se garantiza el derecho al honor, a la intimidad personal y familiar y a la propia imagen", y en el art. 18.4: "La Ley limitará el uso de la informática para garantizar el honor y la intimidad personal y familiar de los ciudadanos y el pleno ejercicio de sus derechos". Pero también la Constitución garantiza los derechos de los investigadores: tal es el caso del artículo 20.1b, donde se reconocen y protegen los derechos "a la producción y creación literaria, artística, científica y técnica"; el artículo 44.2, en el que se indica que "los poderes públicos promoverán la ciencia y la investigación científica y técnica en beneficio del interés general”; y el artículo 105.b, donde se establece que la ley regulará "el acceso de los ciudadanos a los archivos y registros administrativos, salvo en lo que afecte a la seguridad y defensa del Estado, la averiguación de los delitos y la intimidad de las personas".
} 
los que interpretan cada caso concreto, y éstos saben muy bien que se exponen a sanciones administrativas o penales ciertas si dejan ver más de la cuenta, mientras que gozan de impunidad si pecan por lo contrario. Un elemental sentido de la prudencia aconseja a los archiveros extremar las precauciones en esta materia.

Al margen de ello, la cláusula introducía el peligroso principio de "acción preventiva" en la regulación de los derechos que tan nefastas consecuencias ha tenido en otros ámbitos, especialmente el de las relaciones internacionales ${ }^{7}$. La estrategia consiste en prohibir el acceso para evitar el mal uso de los datos, lo que genera los mismos problemas que se atribuyen a cualquier solución inspirada en el principio de prevención: que se provoca un perjuicio cierto y real para anticiparse a un peligro hipotético y a menudo dudoso. En este caso, se coarta la libertad de información y el derecho de acceso al patrimonio documental, perjuicio cierto, para anticiparse a un posible mal uso de los datos allí contenidos, peligro sólo probable. Lo que debería considerarse una intromisión ilegítima es «la divulgación de datos privados», y sobre todo si se hace con fines difamatorios, no el acceso a esos datos o su conocimiento a través de la actividad profesional, sea la del archivero o la del investigador. Conviene recordar al respecto, una vez más, lo que decía el añorado profesor Francisco Tomás y Valiente, Presidente del Tribunal Constitucional: "Es posible que el honor, es posible que la intimidad (aunque esto me parece muy difícil) se puedan poner en riesgo [al acceder a los documentos]; pero el riesgo de utilización de un derecho no es en sí mismo razón suficiente para no permitir el ejercicio del derecho" ". La negativa preventiva es fruto de una mera presunción, de la desconfianza sobre cómo utilizará el ciudadano la información. Al adoptarse como norma, se exagera el riesgo y se suprime la posibilidad de cometer un delito de información con el taxativo expediente de cerrar el acceso a las fuentes de información. De esta manera, todo investigador que solicita ver documentos de menos de cincuenta años que contengan datos de carácter personal pasa a ser considerado inmediatamente un delincuente en potencia, alguien a quien hay que impedir que acceda a los medios con los que podría cometer un delito.

Posteriormente, la LOPDP 15/1992 desarrolló mucho más el control de este tipo de datos, introduciendo algunas novedades que resultaron letales para el acceso a la documentación custodiada en depósitos documentales oficiales ${ }^{9}$. La protección de los datos de carácter personal se hizo sin distinción entre archivos históricos y administrativos, y con un carácter absoluto inapropiado: alcanzaba no sólo a los datos informáticos o automatizados ${ }^{10}$, sino a los registrados "en cualquier soporte físico",

7 Este argumento es el que desarrollábamos en el art. ya citado de Antonio NIÑO: "La acción preventiva y el acceso a los archivos históricos".

8 Justicia en Guerra. Jornadas sobre la Administración de Justicia durante la Guerra Civil Española:, Madrid, M $^{\circ}$ de Cultura, 1990, p. 630.

9 Esta ley venía a sustituir una anterior, mucho más lógica atendiendo a su mismo título: Ley Orgánica 5/1992 de Regulación del Tratamiento Automatizado de los Datos de Carácter Personal. Su espíritu fue el de regular la creación de bases de datos con la finalidad principal proteger los datos personales del tráfico de información, pero no se tuvo en cuenta la especificidad de los documentos originales de archivos, ignorando su posible valor secundario.

10 Aunque el art. 4. 2. dice «Los datos de carácter personal objeto de tratamiento no podrán usarse para finalidades incompatibles con aquellas para las que los datos hubieran sido recogidos». Obsérvese que se refiere a «datos de carácter personal objeto de tratamiento», es decir, los contenidos en ficheros automatizados 
y aunque la intención era prevenir el riesgo de "tratamiento" inadecuado de esos datos cuando formaban parte de ficheros o registros informáticos, en la práctica se aplica a cualquier "acceso" que se quiera hacer a esos datos. La confusión entre tratamiento de datos incluidos en ficheros, y acceso a los propios documentos, ha sido un error continuo desde entonces. Peor aún, la protección alcanzaba no sólo a los datos especialmente protegidos que constituyen el núcleo duro de la intimidad, sino "a los de cualquier otra índole", como "cualquier información concernientes a personas físicas identificadas o identificables". Es decir, la protección se extendía a los datos nominativos o meramente identificativos. Esta expansión desmesurada del concepto de intimidad personal, avalada por un órgano inspector y sancionador, la Agencia Española de Protección de Datos, ha sido la fuente de todas las confusiones, pues de ahí se derivaban graves contradicciones entre la citada ley y otras regulaciones que tratan de proteger los mismos u otros derechos.

La misma ley considera datos especialmente protegidos (art. 7) los datos de carácter personal que revelen la ideología, afiliación sindical, religión y creencias, así como los que hagan referencia al origen racial, a la salud y a la vida sexual. Estos datos sólo podrán ser recabados con el consentimiento expreso de las personas, pero establece una excepción «cuando la cesión se produzca entre Administraciones públicas y tenga por objeto el tratamiento posterior de los datos con fines históricos, estadísticos o científicos». No solamente parece claro que estas limitaciones no se refieren a los Archivos Históricos, que se rigen por su propia ley, sino que establece un régimen especial de acceso sin limitaciones cuando se haga con esos fines. Además, la disposición adicional tercera dice que la regla del consentimiento expreso de los afectados o el transcurso de 50 años desde la fecha de los expedientes sólo se aplica, según esta ley, «a los expedientes específicamente instruidos al amparo de las derogadas Leyes de Vagos y Maleantes, y de Peligrosidad y Rehabilitación Social que contengan datos de cualquier índole susceptibles de afectar a la seguridad, al honor, a la intimidad o a la imagen de las personas». Por lo tanto, y por analogía, la limitación que la LPHE establecía para el acceso a los documentos que contienen «datos personales... que puedan afectar... a su honor, a la intimidad de su vida privada y familiar y a su propia imagen», podría entenderse como aplicable exclusivamente a los documentos que contienen datos sobre la ideología, afiliación sindical, religión, creencias, origen racial, salud y vida sexual de las personas. En estos casos podría estar justificada la negativa de acceso con carácter preventivo por cuanto la difusión de esa información podría causar daños irreparables a las personas. El castigo por haber difundido información de carácter íntimo como la señalada difícilmente reparará completamente el daño sufrido por la víctima. Pero la protección de esta ley también se extiende a los documentos que contienen otros datos de carácter personal. Entendemos que en ningún caso cabe incluir en el ámbito de la intimidad datos personales identificativos (nombre, DNI, domicilio), ni las actividades relacionadas con la administración, ni toda la serie de informaciones, aunque sean personales y

\footnotetext{
o susceptibles de serlo, en consonancia con el precepto constitucional ya citado: art. 18.4 CE. Aparentemente la intención era proteger los datos personales contenidos en ficheros, en los que concurre la circunstancia de estar dispuestos de manera que puedan ser tratados informáticamente, no a datos personales contenidos en documentos de archivo o en expedientes administrativos.
} 
«nominativas», que se suelen reunir en los expedientes que habitualmente se forman en el trámite administrativo. ¿Acaso el nombre y apellidos son datos que afectan a la intimidad? Deberían distinguirse, por lo tanto, los datos meramente personales de aquellos de carácter privado y los íntimos. Los documentos administrativos contienen con frecuencia datos personales de carácter individual, pero no íntimos.

La LOPDP 15/1999 también recogía ese principio de acción preventiva consistente en impedir el acceso a los datos, no su difusión. Sin embargo, sólo se aplica a datos referentes a personas vivas - detalle que es habitualmente ignorado por las personas encargadas de dictaminar la accesibilidad de los datos-, por lo que es más permisiva en este aspecto que la LPHE, que establece una reserva de 25 años aún en el caso de personas fallecidas.

Es cierto que las leyes que estamos examinando incurren en una grave ambigüedad e indefinición en estos aspectos, cuando no en incoherencias manifiestas. En la práctica, la extensión más allá del sentido común del concepto de «intimidad» y la aplicación fundamentalista de las cautelas que establece la ley pueden llevar, están llevando de hecho, a situaciones absurdas que ni siquiera pudieron ser previstas por el legislador ${ }^{11}$. El problema de fondo, como se puede ver, es el desequilibrio que se ha producido entre la protección que recibe el derecho a la intimidad de las personas y el derecho de acceso a la información que asiste a los ciudadanos. Ciertamente, la cuestión está en compaginar ambos derechos, y cuando se produce una confrontación deberían ser los tribunales de justicia, no la administración, la que ponderara adecuadamente el equilibro entre derechos fundamentales igualmente fundados. ¿Existe jurisprudencia al respecto?

Los historiadores pusimos muchas esperanzas en los efectos de una sentencia del Tribunal Constitucional que aclaraba algunos de los aspectos que aquí tratamos ${ }^{12}$. La sentencia desestimaba el recurso de amparo presentado por los hijos de don Carlos Trias Bertrán, por intromisión en el derecho al honor protegido por el art. 18.1 CE, contra un documental difundido en el programa titulado Sumaríssim 477. El padre de los recurrentes era citado en algunos documentos de archivo como el delator y denunciante de un dirigente de Convergencia Democrática de Cataluña que, posteriormente, fue condenado y fusilado por un tribunal militar en la posguerra civil. En este caso se contraponía la libertad científica del historiador al difundir un dato histórico con la supuesta intromisión en el honor de las personas por la revelación de datos privados. Obsérvese que en este caso no es sólo el acceso a la documentación lo que se cuestionaba, sino incluso el derecho a difundir datos de carácter histórico que afectaban al honor de las personas. En sus fundamentos de derecho, el Tribunal Constitucional señalaba que:

11 El propio Tribunal Constitucional advirtió del peligro que implica una estimación subjetiva de la Administración en la aplicación de esta ley. En su sentencia 292/2000, de 30 de noviembre, por la que se declara la inconstitucionalidad de diversos artículos (21.1 y 24.1 y 2) de la ley Orgánica 15/1999, al hablar de las limitaciones del derecho fundamental establecidas en la Ley, se advierte que «éstas pueden vulnerar la Constitución si adolecen de falta de certeza y previsibilidad en los propios límites que imponen y su modo de aplicación (...) lo que no sólo lesionaría el principio de seguridad jurídica (...) sino que al mismo tiempo dicha Ley estaría lesionando el contenido esencial del derecho fundamental así restringido...».

12 STC 43/2004, de 23 de marzo de 2004. 
... el presente proceso constitucional aconseja no limitar nuestro análisis a la posible confrontación del mentado derecho fundamental (el derecho al honor) con las libertades de expresión e información, sino que es preciso (...) aludir igualmente a la libertad científica del historiador. [Y añadía al respecto]: La posibilidad de que los contemporáneos formemos nuestra propia visión del mundo a partir de la valoración de experiencias ajenas depende de la existencia de una ciencia histórica libre y metodológicamente fundada. Sin diálogo con los juicios de los demás (con los del historiador, en lo que aquí importa) no resulta posible formar el propio juicio. No habría tampoco espacio - que sólo puede abrirse en libertad - para la formación de una conciencia histórica colectiva.

Esta sentencia del Tribunal Constitucional era pues una clara defensa del "derecho de libre información" de los historiadores, además del derecho a difundir sus resultados: "el uso de la libertad científica" de informar sobre un hecho histórico no tiene porqué "producir lesión alguna en el derecho al honor" si se trata de "concretos hechos, cuya realidad resulta indubitada". Como sostiene el propio fallo, "la distancia en el tiempo diluye la condición objetiva de la personalidad frente al ejercicio de las libertades del art. 20", además de que "si la información es veraz y los hechos tienen relevancia pública, no quedan protegidos por el derecho al honor". La sentencia concluía con una defensa de la libertad científica frente a las posibles trabas jurídicas: "El ejercicio de nuestra jurisdicción en la garantía de los derechos fundamentales (...) no sirve para enjuiciar la Historia, y menos aún para cambiarla o silenciar sus hechos, por mucho que éstos o las interpretaciones que de los mismos se puedan hacer resulten molestos y penosos para sus protagonistas o, como es el caso, para sus descendientes." Pero, al parecer, los historiadores pusimos unas esperanzas injustificadas en que esta sentencia cambiara las cosas. Ninguna consecuencia práctica se derivó de ella, ni en el terreno normativo ni en el de la actuación corriente de la administración.

La norma aprobada recientemente, el RDSEA 1708/2011, se presenta con el loable propósito de resolver el problema de esa difícil compatibilidad en el ámbito de los archivos públicos. Entre sus propósitos está sistematizar, en la medida de lo posible, la diferente legislación que hemos citado. El preámbulo, como suele ser habitual, está lleno de buenas intenciones: "Esta norma pretende, asimismo, facilitar el ejercicio del derecho de acceso de los ciudadanos a los archivos y documentos administrativos, mediante la clarificación de los criterios fijados en la muy diversa legislación aplicable". También se manifiesta de forma expresa el deseo de "suprimir incertidumbres y eliminar cualquier ocasión de arbitrariedad", y de respetar "el delicado equilibrio que debe mantenerse entre la salvaguarda del derecho fundamental a la protección de datos personales (...) y el derecho de acceso a documentos y archivos". En realidad, como veremos, no sólo no resuelve estos problemas sino que los empeora ${ }^{13}$. En principio este Real Decreto no es más que un desarrollo reglamentario, y por lo tanto no puede alterar las disposiciones contenidas en las principales leyes ya examinadas:

13 Sobre el proceso de elaboración de este RD y sus características, vid. Blanca DESANTES FERNÁNDEZ, "El proceso de acceso desarrollado en el RD 1708/2011, de 18 de noviembre. Entre la realidad y el deseo", Tabula, 15 (2012), pp. 109-146. Es significativo que esta norma se aprobara en el último Consejo de Ministros de un gobierno presidido por José Luis Rodríguez Zapatero que ya actuaba técnicamente como gobierno en funciones. 
la LPHE 16/1985, la LRJAPPAC 30/1992, y la LOPDP 15/1999 ${ }^{14}$. Por ello, no hace sino repetir la lista de exclusiones ya establecida:

Artículo 26. Acceso restringido.1. Los documentos conservados en los archivos incluidos en el ámbito de aplicación de esta norma serán de libre acceso, salvo cuando les afecte alguna de las limitaciones previstas en la Constitución y en las Leyes. En particular, serán de acceso restringido los documentos clasificados según lo dispuesto en la normativa sobre secretos oficiales, los documentos que contengan información cuya difusión pudiera entrañar riesgos para la seguridad y la defensa del Estado o interferir en la averiguación de los delitos o la tutela judicial efectiva de ciudadanos e instituciones, así como los declarados reservados por una norma con rango de Ley y aquellos que contengan datos personales a los que se refiere el artículo 28 .

En todos estos casos el acceso está condicionado a la obtención de autorización previa. Sin embargo, las condiciones para conceder dicha autorización, que el RD pretende aclarar, se inclinan siempre por la norma más restrictiva. En el artículo 28, apartado 2 se dice que: “... serán accesibles los documentos con datos personales que puedan afectar a la seguridad o intimidad de las personas cuando hayan transcurrido veinticinco años desde el fallecimiento de los afectados". El decreto se inclina por el plazo temporal que establecía la LPHE, en vez de la libertad de acceso en el caso de personas fallecidas que establecía la LOPDP. Peor aún, el mismo artículo añade una condición: "Cuando no fuera posible conocer la fecha o el hecho del fallecimiento y el documento o documentos solicitados posean una antigüedad superior a cincuenta años, el acceso se concederá si, atendidas las circunstancias del caso, se entiende razonablemente excluida la posibilidad de lesión del derecho a la intimidad personal y familiar o el riesgo para la seguridad del afectado y siempre de conformidad con la normativa de protección de datos". De nuevo una regresión: la LPHE establecía la apertura de los documentos en cuestión en todo caso una vez transcurridos 50 años desde su creación; la redacción de este artículo permite alargar ese plazo sine die si alguien, ¿quién?, entiende "razonablemente" que no se excluye la posibilidad de lesión de derechos. No es éste el único aspecto en el que la nueva norma interpreta las leyes existentes de la forma más restrictiva posible ¿Cómo es posible que un real decreto que pretende desarrollar una ley imponga nuevas y más duras condiciones que la ley no contemplaba? ${ }^{15}$. ¿Y qué decir de una norma que pretende "clarificar" las leyes existentes y que introduce condiciones abstrusas o excesivamente genéricas?.

14 A las que hay que añadir las últimas disposiciones que tratan tangencialmente el derecho de acceso, como la Ley 11/2007, de 22 de junio, de Acceso Electrónico de los Ciudadanos a los Servicios Públicos, y la Ley 52/2007, de 26 de diciembre, por la que se reconocen y amplían derechos y se establecen medidas a favor de quienes padecieron persecución o violencia durante la guerra civil y la dictadura, más conocida como Ley de la Memoria Histórica. Esta última no ha supuesto el más mínimo avance en el sistema normativo del derecho de acceso, a pesar de que su art. 22. Derecho de acceso a los fondos de los archivos públicos y priva$d o s$, establecía taxativamente que "a los efectos de lo previsto en esta Ley, se garantiza el derecho de acceso a los fondos documentales depositados en los archivos públicos y la obtención de las copias que se soliciten".

15 La LPHE establece taxativamente que los documentos con datos personales son accesibles, en todo caso, una vez transcurridos 50 años. La misma LOPD, 11.2.a sostiene lo mismo. El mismo criterio mantuvo el Ministerio de Cultura en los informes previos a la elaboración del RDSEA, como explica Blanca DESANTES, art. cit. Sin embargo, el nuevo RDSEA ni siquiera respeta los plazos temporales ya existentes, los únicos que 


\section{Las malas prácticas en la aplicación de las normas que limitan la libertad de acceso a la documentación}

Pero más allá de las ambigüedades e indefiniciones de las leyes, lo que está entorpeciendo el acceso de los investigadores a los archivos públicos son algunas malas prácticas que se han extendido entre los responsables de la administración. Las más graves ya las hemos señalado: la práctica de aplicar leyes en ámbitos a los que no estaban dirigidas, como es la utilización de la LOPDP -ley que, recordemos, no establece límites temporales algunos a la proyección de datos, salvo el fallecimiento de las personas afectadas- en la regulación del acceso a los archivos históricos, sin considerar que éstos tienen su propia regulación, y sin atender a las excepciones que la propia ley establece en beneficio de la investigación histórica y científica.

El RDSEA 1708/2011 introduce una novedad a este respecto; en una disposición adicional sexta dedicada al Régimen de acceso a los Archivos Históricos de titularidad y gestión estatal, se hace una declaración a favor de este tipo de archivos: "Las disposiciones del presente Real Decreto se aplicarán sin perjuicio de las reglas específicas de acceso a los fondos de los Archivos Históricos de titularidad y gestión estatal, en razón de su carácter de archivos abiertos al público, siempre que resulten más favorables al derecho de acceso". Esta es la buena noticia; la mala noticia es que esta disposición adicional sólo se refiere a los archivos de gestión estatal, y se restringe a los "históricos". Pero la legislación no se ha preocupado por definir qué debe entenderse por archivo histórico. El criterio diferenciador de los archivos, entre administrativos e históricos, se ha ido difuminando con el tiempo y sustituyendo por el sistema de ciclo vital de los documentos. Tal y como el propio decreto clasifica a los distintos tipos de archivos, se reserva el calificativo de "histórico" a los depósitos donde recala la documentación clasificada de conservación permanente; ni los Archivos Centrales de los Ministerios y de los organismos públicos dependientes de los mismos, -aunque algunos contienen documentación medieval-, ni los Archivos Intermedios reciben ese calificativo. Entre los llamados "intermedios" se encuentra el Archivo General de la Administración, importantísimo para la investigación histórica porque acumula gran cantidad de fondos con más de cincuenta años de antigüedad. Es conocido el hecho de que el sistema de transferencias previsto en la administración civil, en consonancia con el ciclo vital de la documentación, es sumamente deficiente por falta de medios, y los documentos pueden dormir el sueño de los justos en los archivos centrales o intermedios, de carácter administrativo, sin pasar jamás a los archivos históricos como el Archivo Histórico Nacional, saturado e incapaz de recibir nuevas remesas de documentación.

Otra mala práctica frecuente y especialmente perniciosa es la confusión entre los datos personales genéricos y aquellos otros expresamente protegidos por la ley, es decir, únicamente aquellos que puedan afectar al honor, a la intimidad o a la imagen de las personas. Los datos contenidos en el expediente de un estudiante no pertenecen a la esfera privada e íntima de la persona por cuanto la información que allí se con-

aportaban una mínima seguridad jurídica al delimitar con precisión cuándo se puede ejercer el derecho de acceso sin restricciones. 
tiene se refiere exclusivamente a su actividad académica ${ }^{16}$. Tampoco el expediente de un funcionario suele contener datos sobre sus inclinaciones sexuales, sus prácticas religiosas o informaciones por el estilo. Sin embargo, es habitual que documentos oficiales de este tipo se protejan de la consulta alegando que contienen datos de carácter personal.

El siguiente ejemplo puede servir de muestra: la Instrucción de 12 de julio de 2006, de la Secretaría General Técnica del Ministerio del Interior, por la que se dictaban las normas sobre el acceso y la consulta de documentos en los archivos dependientes de ese Ministerio, establecía que:

Se considerarán datos pertenecientes a la intimidad de las personas los nombres y otros datos personales, reflejados en los expedientes como resultado del ejercicio de sus funciones, pertenecientes a funcionarios de instituciones penitenciarias así como a funcionarios policiales y cualesquiera otros empleados públicos de la Seguridad del Estado que figuren en actuaciones policiales y judiciales ${ }^{17}$.

La instrucción hacía así una interpretación tan extensa de lo que debían ser datos personales protegidos que en la práctica impedía la consulta de la inmensa mayoría de la documentación allí custodiada ${ }^{18}$. Precisamente si se trata de expedientes formados "como resultado del ejercicio de sus funciones", no es previsible que incluyan datos sobre la intimidad de los funcionarios. Cualquiera puede sospechar que lo que se pretende proteger no es la intimidad de los funcionarios policiales o judiciales, sino sus actuaciones como funcionarios al servicio del Estado, algo incompatible con un estado de derecho. El caso más cínico de este uso perverso del derecho a la intimidad de los funcionarios se produjo cuando en unas declaraciones del portavoz del Departamento de Defensa de los Estados Unidos, realizadas en el 2004, se afirmaba que no se hacía público el material gráfico que mostraba las torturas cometidas por soldados de ese país en la tristemente célebre cárcel de Abu Graib, en Iraq, porque «hay otros factores, como el derecho a la intimidad de los que aparecen en las imágenes y el hecho de que los testimonios pueden ser considerados pruebas

16 Pero esta fiebre por la protección de los datos personales se ha extendido a todos los ámbitos de la actividad, dando lugar a situaciones grotescas y absurdas. Hasta en las propias universidades se han dictado instrucciones instando a los profesores a declarar los ficheros en los que reúnan datos personales, como fruto de su actividad investigadora o docente, y se ha prohibido hacer públicas las calificaciones de los alumnos para no violar "el honor" de los afectados.

17 La instrucción, además de prohibir el acceso a los documentos "sospechosos", establecía una cautela suplementaria y, en este caso, redundante: “9. Cuando así se estime oportuno, a la luz de las circunstancias del caso concreto, se podrá requerir al solicitante declaración escrita por la que se comprometa a no utilizar la información ni las reproducciones suministradas con fines que puedan afectar al derecho al honor, la intimidad y la propia imagen, o a aquellos otros reconocidos por la legislación reguladora".

18 Hay otras formas de preservar la identidad de los funcionarios o de las personas citadas en la documentación policial. En un archivo policial de características similares, la División Central Archivo y Fichero de la Dirección de Inteligencia de la Policía de la Provincia de Buenos Aires (DIPPBA), que en la actualidad custodia y gestiona la Comisión por la Memoria de la Provincia de Buenos Aires, se ha adoptado una solución mucho más respetuosa con el derecho de acceso: se brinda a la consulta la documentación de este fondo, pero se realiza la disociación de datos, de manera que la información obtenida no pueda asociarse a persona determinada o determinable. Vid. http://www.comisionporlamemoria.org/cuadroclasificacion/ [consultado el $15 / 06 / 2012]$ 
en las investigaciones» ${ }^{19}$. Aquí, la excusa de proteger el derecho a la intimidad se utilizaba, no sólo para conculcar el derecho a la información de los ciudadanos, sino para ocultar unos hechos muy graves que atentaban directamente contra los derechos fundamentales de las personas y de paso cubrir a los responsables de estas torturas.

El RDSEA 1708/2011 no resuelve este problema, sino que más bien lo agrava al extender a los datos meramente identificativos la protección que antes sólo recibían los datos personales susceptibles de afectar a la intimidad y el honor de las personas. $\mathrm{El}$ art. 28.3 señala que "el acceso a documentos que contengan datos nominativos o meramente identificativos de las personas que no afecten a su seguridad o su intimidad, será posible cuando el titular de los mismos haya fallecido o cuando el solicitante acredite la existencia de un interés legítimo en el acceso". Antes esos datos eran libremente accesibles, según la LPHE, ahora no. Sabiendo que son raros los documentos administrativos que no contienen algún tipo de "datos nominativos", eso significa el cierre de la mayoría de los fondos archivísticos a la consulta pública. Para evitar las peores consecuencias de tal medida, se añade una cláusula que introduce una excepción: "A estos efectos, se entenderá que poseen interés legítimo quienes soliciten el acceso para el ejercicio de sus derechos y los investigadores que acrediten que el acceso se produce con una finalidad histórica, científica o estadística". De modo que los investigadores tendrán que "acreditar" que sus fines son honestos para acceder a datos que hasta ahora eran de libre consulta en los depósitos con fondos históricos.

Esa cláusula, en realidad, no hace otra cosa que recoger las excepciones que las propias leyes contienen para proteger la investigación científica de una aplicación abusiva de la protección de la intimidad personal. Pero estas excepciones, que habían sido sistemáticamente ignoradas hasta ahora, se recuerdan únicamente para permitir el acceso a un tipo de datos que no estaban sometidos a ningún tipo de limitación en la LPHE. Efectivamente, las leyes de protección de datos, a pesar de su dureza, contienen excepciones para proteger los intereses de la investigación científica, y las investigaciones con fines históricos en particular, aun cuando se trate de documentos que contengan datos relacionados con la intimidad de las personas ${ }^{20}$. Ningún derecho reconocido, tampoco el derecho a la intimidad, puede tener un carácter absoluto, y estas cláusulas que introducen excepciones a la protección de datos de carácter personal suponen una cierta y lógica ponderación entre ese derecho y el derecho de acceso ${ }^{21}$. En la práctica, sin embargo, no han sido tomadas en consideración, probablemente porque el derecho de acceso no ha sido desarrollado reglamentariamente, mientras que la protección de datos no sólo cuenta con un minucioso desarrollo reglamentario,

19 vid. El País, 11.05.2004.

20 El art. 8.1 de la LOPHI 1/1982, establecía que «no se reputarán, con carácter general, intromisiones ilegítimas las actuaciones autorizadas o acordadas por la Autoridad competente de acuerdo con la ley, ni cuando predomine un interés histórico, científico o cultural relevante». El art. 4.2 de la LOPDP 15/1999 dice: «No se considerará incompatible el tratamiento posterior de estos datos con fines históricos, estadísticos o científicos». Por su parte, el art. 5.5. también exime de informar de forma expresa a los interesados del tratamiento de sus datos «cuando el tratamiento tenga fines históricos, estadísticos o científicos». Y por último, el art. 11 prevé el consentimiento de los interesados para la comunicación de los datos personales a terceros, pero establece de nuevo una excepción «cuando la cesión se produzca entre Administraciones públicas y tenga por objeto el tratamiento posterior de los datos con fines históricos, estadísticos o científicos»».

21 Ver el análisis que hace Daniel OCAÑA del carácter no absoluto del derecho a la intimidad en "Ser o no ser...", art. cit., p. 157 y sig. 
sino con una Agencia Estatal que vigila su cumplimiento y tiene una capacidad sancionadora contundente. Estas cláusulas, que introducen una excepción a favor de los investigadores, no suponen ningún privilegio en beneficio de un gremio particular, como alguien ha sostenido, sino que están de acuerdo con el Convenio ${ }^{\circ} 108$ de 28 de enero de 1981 suscrito por los Estados del Consejo de Europa que ya contemplaba en su art. 9.3 la posibilidad de acceso a los ficheros de datos de carácter personal por razones de investigación científica, y son coherentes, además, con la necesidad de cumplir con la Directiva 95/46 de la Unión Europea, de 24 de octubre, en su art. 6.1.b). Sin estas cláusulas, por ejemplo, no serían accesibles ni siquiera los inventarios o los índices de muchos archivos que facilitan la búsqueda de la documentación utilizando criterios onomásticos. Pero, como decíamos, estas excepciones a favor de la investigación científica nunca se habían aplicado. Ahora el nuevo RDSEA 1708/2011 las saca a la luz y las reproduce, únicamente cuando se trate de "datos nominativos o meramente identificativos de las personas que no afecten a su seguridad o su intimidad". Pero si no afectan ¿qué necesidad había de autorizar el acceso por razones científicas?

El más generalizado de los errores, sin embargo, es la extensión abusiva de las excepciones en el derecho de acceso hasta convertirlas de facto en la norma general. En una carta de denegación de acceso, similar a la que reciben continuamente los investigadores, se decía literalmente: «En relación con su petición verbal de acceso al fondo en cuestión (...) siento indicarle que la consulta de dicho fondo sólo podrá efectuarse según vayan transcurriendo los plazos temporales que establece la legislación vigente, y que son cincuenta años desde la fecha de los documentos, veinticinco desde la muerte del afectado (si es conocida) o con autorización expresa de los mismos» ${ }^{22}$. Estos plazos, se decía en la carta, son los previstos en el art. 57.1 de la LPHE. Con esa interpretación, la excepción se eleva a la categoría de norma y el apartado más restrictivo de la ley, destinado a un tipo de documentos muy específicos, se aplica indiscriminadamente a todo un fondo. Se arruina así el principio general establecido en la propia LPHE del libre acceso en los archivos de carácter histórico y, sin más explicaciones, se aplica un sistema de plazos en el que los 50 años desde la fecha de creación del documento se convierte en el periodo de embargo normal.

Otras malas prácticas habituales se refieren a aspectos que podríamos llamar "técnicos". La más frecuente de ellas es la falta de motivación de las decisiones de denegación del acceso, lo que impide recurrirlas por el procedimiento administrativo. Las denegaciones de consulta carecen a menudo de los requisitos exigibles a cualquier resolución administrativa, en especial la expresión de los motivos y de los recursos que contra la misma procedan, los plazos y el órgano ante el que hubieran de presentarse, etc. En otras ocasiones las denegaciones de acceso remiten a las normas legales que estamos analizando acumulando las alusiones a varias de ellas: LRJPAC, LPHE y LOPDP, sin especificar la incidencia específica de cada una. La Administración debería justificar la aplicación de una u otra norma específica en cada caso, y ponderar la importancia del derecho de protección de datos personales respecto al derecho de acceso, especialmente cuando opta por aplicar alguna excepción que res-

22 Carta del 2 de abril de 2003, firmada por la directora del Archivo General de la Administración. 
tringe la norma general. Las denegaciones de acceso mal motivadas impiden que se pueda controlar la toma de decisión, y en su caso poner los recursos administrativos o contencioso-administrativos que corresponda. Al respecto cabe señalar lo que dice la Recomendación $n^{\circ}$ R(2000)13 del Comité de Ministros del Consejo de Europa sobre una política europea en materia de comunicación de los archivos (adoptada el 13 de julio del 2000), en la que se establece que: «III.11. Cualquier denegación de comunicación o de autorización excepcional de acceso debe ser motivada por escrito y el autor de la demanda debe tener la facultad de recurrir contra una decisión negativa, en última instancia ante la justicia». De hecho, es lo mismo que establecía el ordenamiento jurídico español en la LRJAPPAC 30/1992 en su art. 89.3, la obligación de resolver cuando se hace una solicitud formal a la administración, algo que no siempre se ha respetado en el ámbito de los archivos públicos.

En un artículo anterior ya hemos hecho referencia a algún caso concreto ${ }^{23}$ en el que se llegó a lo que bien podríamos llamar un bucle kafkiano: primero la dirección de un archivo estatal como el Archivo General de la Administración niega la solicitud de acceso a un fondo documental en su conjunto alegando que contiene datos personales; cuando se recurre por la vía administrativa al entonces Ministerio de Cultura, responden que en realidad la decisión de la dirección del archivo no era una resolución administrativa sino un escrito meramente informativo. Las denegaciones de carácter «informativo», al parecer, gozaban del privilegio de no ser recurribles. Si entonces, para salir del impasse, el investigador presenta una solicitud formal ante el Ministerio, la administración se abstiene de resolver, y cuando se reclama la resolución afirmativa por silencio administrativo, tal y como prevé la ley, entonces el Ministerio responde que la falta de respuesta a la solicitud no debe interpretarse afirmativamente, como es la norma, sino que el caso está inserto en una excepción de la ley - la que protege bienes de dominio público o demaniales-, y que el silencio es por lo tanto denegatorio ${ }^{24}$.

A veces lo más difícil es conseguir que la autoridad administrativa se pronuncie, no ya sobre el fondo, sino sobre la forma del asunto, es decir: quién tiene facultad para denegar el acceso a una documentación de archivo, cómo han de interpretarse las restricciones que establece la ley, qué recursos cabe interponer ante prohibiciones arbitrarias y no fundamentadas, qué procedimientos hay para solicitar el acceso por la vía excepcional a una documentación determinada, etc. Silencios como éstos pueden ser un indicador de hasta qué punto la administración española sigue estando regida por los principios de un Estado hermético y secretista, que trata a las personas como «administrados» más que como ciudadanos.

\footnotetext{
23 Antonio NIÑO: "La acción preventiva y el acceso a los archivos históricos", art. cit., nota 4.

24 Hasta la entrada en vigor del RDSEA 1708/2011, en el Archivo General de la Administración se seguía utilizando un procedimiento de valoración que, como señala Francisco FERNÁNDEZ CUESTA, "Servir y proteger: la valoración de la accesibilidad en el Archivo General de la Administración”, Tabula, 15 (2012), p. 215: “carecía de determinadas garantías esenciales: en primer lugar, no establecía un plazo para su ejecución (...) Además, los resultados del mismo no podían ser objeto de impugnación. Por último, no motivaba de forma expresa la exclusión de una determinada unidad, limitándose a señalar la normativa legal en virtud de la cual se había restringido su consulta". Véase José Luis LATORRE y Mercedes MARTÍN-PALOMINO, Metodología para la identificación y valoración de fondos documentales, Madrid, MECyD, 2000.
} 
El RDSEA 1708/2011, al que estamos aludiendo, viene a recordar algo que ya estaba recogido en la ley desde hace 22 años pero que no se practicaba en los archivos: la obligación de establecer "un procedimiento administrativo común para la solicitud de acceso a los documentos conservados en los archivos de la Administración General del Estado". Efectivamente, allí se regula el procedimiento introduciendo las mínimas garantías que ya se contemplaban en la LRJAPPAC 30/1992. Se fija, por fin, un procedimiento de solicitud de acceso, tramitación y resolución, con la obligación de notificar por escrito, indicar los recursos que procedan, y sobre todo de motivar las denegaciones. Es más, se dice expresamente que "transcurrido el plazo máximo para resolver sin haberse notificado resolución expresa, la solicitud de acceso se entenderá estimada". Pero, a cambio, se introduce la necesidad de acreditar una finalidad científica, histórica o cultural relevante para la consulta directa de los documentos, condición que hasta ahora no existía ${ }^{25}$.

Nada dice el RDSEA, sin embargo, de la posibilidad de autorizaciones excepcionales de acceso, algo que está recogido en las normas nacionales e internacionales que regulan este derecho. Cualquier negativa de acceso debería acompañarse de la información sobre las vías que la ley ofrece para solicitar autorizaciones administrativas o excepcionales. Mientras que en otros países esta es la vía normal para conseguir la desclasificación de series documentales, en las denegaciones de acceso que se reciben de los archivos españoles no se suele hacer mención a esta posibilidad. Sin embargo, esta posibilidad está expresamente contemplada en la propia LPHE, en su art. $57 \mathrm{~b}$ ), que prevé un procedimiento para salvar las restricciones que la propia ley establece: «No obstante lo dispuesto en el párrafo anterior, cabrá solicitar autorización administrativa para tener acceso a los documentos excluidos de la consulta pública. Dicha autorización podrá ser concedida, en los casos de documentos secretos o reservados, por la Autoridad que hizo la respectiva declaración, y en los demás casos, por el Jefe del Departamento encargado de su custodia». Con ello está relacionada también la Recomendación ya citada del Comité de Ministros del Consejo de Europa III.9: "Las reglas aplicables deben prever la posibilidad de solicitar de la administración competente una autorización excepcional de acceso a los documentos no comunicables libremente".

Otra mala práctica habitual era la suplantación de funciones y la marginación de los organismos encargados expresamente de regular el régimen de acceso. La propia LPHE, en su art. 58, establece que «el régimen de acceso e inutilidad administrativa de tales documentos (los de la Administración del Estado) corresponderá a una Comisión Superior Calificadora de Documentos Administrativos». Entre las competencias asignadas a dicho órgano está «el estudio y dictamen sobre... la accesibilidad y utilización de los documentos y series documentales» ${ }^{26}$. Desde entonces muchos organismos públicos han ido creando sus propias Comisiones Calificadoras, encargadas de proponer criterios sobre el régimen de acceso de los documentos, y también

\footnotetext{
25 Curiosamente, si se acredita un interés relevante de ese tipo se puede obtener la "entrada a la zona de depósitos de los archivos", posibilidad que no era reclamada por los investigadores. Bastaría con poder acceder a los documentos originales, aunque fuera en las salas de lectura habilitadas en la mayoría de los archivos.

26 Su composición y funcionamiento no se reguló hasta el Real Decreto 139/2000, de 4 de febrero, sustituido por otro Real Decreto 1401/2007, de 29 de octubre.
} 
de informar las solicitudes de acceso a documentos excluidos de la consulta pública. Por lo tanto, son estos órganos colegiados, y no el funcionario de turno a su propio arbitrio, quien tiene competencias para denegar el acceso a determinada documentación por considerarla incluida en la excepción prevista en la ley. Sin embargo no era infrecuente, al menos hasta ahora, que los funcionarios directamente responsables de los archivos se arrogaran la competencia de otorgar o denegar el acceso, sin mayor formalidad y a su libre albedrío. El último RDSEA 1708/2011 no mejora las cosas en este terreno sino que las empeora. Añade una cláusula sorprendente que deja al arbitrio de los archiveros la concesión del acceso incluso cuando los documentos no han sido excluidos por alguna causa legalmente justificada:

26.4. Con carácter excepcional, el responsable del archivo podrá restringir cautelarmente el acceso a aquellos documentos o series documentales que, sin haber sido objeto de exclusión de consulta pública, pudieran incurrir, a su juicio y a la vista de su contenido, en alguna de las limitaciones previstas en las leyes.

Se trata de una disposición sorprendente, que convierte a los archiveros en censores con poder discrecional para denegar el acceso a documentos que son públicos, en principio, si "a su juicio" contienen información que no debe ser consultada, sin más obligación que informar a la Comisión Superior Calificadora de Documentos Administrativos. El propio Ministerio de Asuntos Exteriores y Cooperación estimaba que este artículo no se ajusta a la LSO 9/1968, ni a la LPHE 9/1985, que limitan claramente los órganos competentes para la declaración de las materias clasificadas ${ }^{27}$. La cláusula otorga a los responsables de archivos una responsabilidad impropia y peligrosa, pues les obliga a dictaminar sobre derechos que presentan una notable dificultad de interpretación. El archivero no es un censor, pero cuando se le convierte en intérprete de leyes que no son suficientemente claras en lo que se refiere al acceso, queda expuesto al riesgo de ser acusado de arbitrariedad ${ }^{28}$. En caso de duda ante la "peligrosidad" de determinados documentos y fondos, a nadie extrañará que los responsables de los archivos opten por el criterio más restrictivo posible guiados por un elemental sentido de autoprotección, ya que no hay sanción por exceso de rigorismo, pero sí por falta de diligencia en la ocultación de la información protegida. El artículo 26.4 no solo les impone una pesada carga, sino que les responsabiliza de manera indirecta por las posibles filtraciones de documentación sensible aunque no hubiera sido clasificada formalmente. Y ello sin proporcionarles a cambio instrumentos adecuados -como medios humanos y materiales suficientes- para ejercer el control efectivo de la documentación.

27 Informe de 4 de noviembre de 2011 en el que se señalaban numerosas incoherencias y errores del RDSEA 1708/2011, citado por Blanca DESANTES FERNÁNDEZ, "El proceso de acceso...", art. cit., nota 47.

28 Después de resaltar la telaraña de regulaciones "de ordinario contradictorias o casi ininteligibles", Daniel OCAÑA se cuestiona el papel que le corresponde al archivero, a menudo el único interlocutor del ciudadano, y concluye reconociendo que "la denegación de acceso a los documentos solicitados por el ciudadano muchas veces obedece bien al desconocimiento de funcionarios y responsables políticos del deber de otorgarlo o bien a la determinación arbitraria del carácter reservado de la información", Daniel OCAÑA, "Ser o no ser...", art. cit., p. 152. 
Esta falta de medios puede ser, paradójicamente, el motivo inconfesable de la cláusula anterior. Las carencias en los archivos públicos españoles hace que sea frecuente la habitual falta de control archivístico previo sobre las condiciones de acceso a la documentación. En los fondos que no han recibido ningún tratamiento archivístico -y éstos son una parte importante de todos los que se conservan en los archivos públicos- no se pueden valorar sus condiciones de accesibilidad. Como consecuencia, en los inventarios de los grandes depósitos no consta habitualmente ninguna mención a plazos ni condiciones de acceso, aunque contengan documentación que podría ser no comunicable. Esto se explica porque, a menudo, el instrumento de descripción utilizado por los archiveros y por los mismos investigadores es la misma relación de entrega o índice de remisión elaborado en el momento de la transferencia. Esa falta de tratamiento archivístico previo hace que sea en el momento de solicitar la consulta cuando los archiveros tengan que decidir sobre las condiciones de accesibilidad, sin tiempo y a menudo sin medios para juzgar sobre los datos contenidos en un gran volumen de documentación. Las limitaciones técnicas o archivísticas pueden convertirse así en otra excusa para limitar el derecho de acceso.

Citaremos una mala práctica más: la extensión abusiva de las restricciones de acceso, que se justifican en ciertos documentos, a series enteras e incluso a fondos completos, con lo que se escamotea la consulta de miles de documentos que no están sujetos a aquellas restricciones. No es infrecuente que la denegación de acceso se refiera no a un documento, expediente, o legajo, sino que se haga de forma genérica para toda una serie o el conjunto de un fondo documental. La unidad de descripción sobre la que ha de hacerse la valoración de accesibilidad debe ser la más específica posible, y la exclusión de la consulta se justifica cuando afecta a documentos concretos, nunca a series o fondos enteros. El artículo 57 de la ley de Patrimonio Histórico Español se refiere expresamente a «documentos», y no a series ni a fondos completos ${ }^{29}$, por ello entendemos que la restricciones al derecho de acceso se deberían aplicar, en su caso, a los documentos que contengan el tipo de datos contemplados expresamente en ese artículo, pero en ningún caso a todo un fondo archivístico indiscriminadamente.

A este respecto, conviene citar una vez más la Recomendación del Comité de Ministros del Consejo de Europa en la que se establece que: «III.10. Si para proteger los intereses mencionados en el artículo 7.1, los archivos solicitados no son libremente comunicables, la autorización excepcional puede ser otorgada para una comunicación por extractos o con ocultación parcial. El utilizador será informado». Afortunadamente, el RDSEA 1708/2011 reconoce esta posibilidad en su artículo 28.4: "se concederá el acceso a documentos que contengan datos de carácter personal, sin necesidad de consentimiento de sus titulares, cuando se proceda previamente a la oportuna disociación de los datos de modo que se impida la identificación de las personas afectadas". Pero no hay que hacerse ilusiones con la mención a la posibilidad de disociación: una manera habitual de saltarse esa recomendación ha consistido en alegar insuficiencia de medios para discriminar entre los documentos accesibles y aquellos protegidos por la ley. Es muy clarificador lo que dice al respecto la propia Secretaría

29 Art. 57: “ 1: La consulta de los documentos constitutivos del Patrimonio Documental Español a que se refiere el art. 49.2 se atendrá a las siguientes reglas..." 
General del Libro, Archivos y Bibliotecas en un informe de 29 de enero de 2003: «La información que pudiera afectar a la intimidad de las personas se encuentra incluida en documentos con información de carácter general de interés para la investigación. En la mayoría de los casos contienen pocos datos que afectan a la intimidad de las personas y muchos datos de interés general, objeto de la investigación. Pero no existen medios técnicos ni personales, asumibles económicamente, que permitan separar ambos tipos de datos». Con lo cual, la prohibición de acceso alcanza a documentos no excluidos de la consulta, únicamente por insuficiencias del servicio o falta de medios.

\section{Los secretos de Estado y las barreras a la investigación}

Pasemos ahora a considerar las restricciones más recientes al acceso a la documentación que se derivan de la ampliación de lo que se consideran secretos de Estado. Como cabe esperar, el punto de partida lo hallamos en la Constitución de 1978. En su artículo 105.b), al garantizarse el derecho de los ciudadanos de acceder a los archivos y registros administrativos, se establece una reserva de ley al excluir "lo que afecte a la seguridad y defensa del Estado". Esta limitación la encontramos en la normativa de todos los países. Ahora bien, tan importante como la afirmación de este límite al derecho de acceso serán los términos en que se define cuáles son esas materias clasificadas y cuál es su régimen de consulta y publicidad, pues en esta definición se dirimen cuestiones fundamentales sobre el control de la acción de los órganos del Estado. De ello dependerá también la posibilidad de que los historiadores reconstruyan fielmente aspectos del pasado que, si en su momento estuvieron justificadamente velados por el manto del secreto, no deben permanecer indefinidamente ocultos so pena de imposibilitar una cabal comprensión de lo ocurrido.

Como no podía ser de otro modo, las leyes posteriores a 1978 recogen y concretan la excepción que en términos generales incluye la Constitución. Así la LPHE de 1985 excluye del derecho de libre consulta los documentos "que afecten a materias clasificadas de acuerdo con la Ley de Secretos Oficiales o [que] no deban ser públicamente conocidos por disposición expresa de la Ley", al igual que aquellos en los que "la difusión de su contenido pueda entrañar riesgos para la seguridad y la defensa del Estado o la averiguación de delitos" (art. 57.1). Ahora bien, que estos documentos no sean de libre consulta pública no quiere decir que no puedan ser consultados bajo ninguna circunstancia, ya que la misma ley establece a continuación que "cabrá solicitar autorización administrativa para tener acceso" a este tipo de documentación. Esta autorización "podrá ser concedida, en los casos de documentos secretos o reservados por la Autoridad que hizo la respectiva declaración, y en los demás casos, por el Jefe de Departamento encargado de su custodia". Tres aspectos cabe destacar de esta formulación. Primero, la remisión a la LSO de 1968, modificada en 1978, para lo que afecte a las "materias clasificadas". Segundo, la distinción entre documentos secretos y reservados, que son las únicas categorías que contempla la LSO, y "los demás casos" de documentos que por disposición legislativa expresa no deban ser públicamente conocidos. Tercero, la posibilidad de consultar los documentos por me- 
dio de una mera autorización administrativa, sin que sea necesario un acto formal de desclasificación de la documentación.

Antes de examinar lo que establece la LSO, vamos a ver cómo la posibilidad de acceder a la documentación sensible para la seguridad y la defensa del Estado se ha ido restringiendo en leyes y desarrollos normativos posteriores. Un primer paso lo encontramos en la LRJAPPAC de 1992, que excluye del derecho de acceso de los ciudadanos a archivos y registros públicos aquellos "que contengan información sobre la Defensa Nacional o la Seguridad del Estado" (art. 37.5). Donde antes se protegía únicamente aquello que pudiera poner en riesgo ambos bienes generales -la seguridad y la defensa-, ahora es toda la documentación que contenga información sobre estas materias la que, según la ley, puede ocultarse a la consulta pública. La extensión de lo así vedado es, lógicamente, muy notable y de difícil justificación, puesto que la mayor parte de la documentación pública sobre la defensa nacional y la seguridad del Estado puede conocerse y difundirse sin peligro alguno para el país, como demuestran cotidianamente los medios de comunicación y publicaciones especializadas.

El siguiente paso lo encontramos en el RDSEA 1708/2011, cuyo artículo 26 repite lo que ya establecía la LPHE al respecto. La involución hacia una lectura más restrictiva del derecho de acceso se introduce en el artículo 27.1, dedicado específicamente a las solicitudes de consulta de aquellos documentos que sean de acceso restringido "por razones de seguridad y defensa del Estado":

Los documentos clasificados de conformidad con lo previsto en la normativa sobre secretos oficiales del Estado estarán excluidos de la consulta pública, sin que pueda concederse autorización para el acceso en tanto no recaiga una decisión de desclasificación por el órgano competente para realizarla.

El ya citado informe del Ministerio de Asuntos Exteriores y Cooperación, de 4 de noviembre de $2011^{30}$, señala justamente que lo dispuesto en este artículo 27.1 es más restrictivo que lo establecido en la LPHE, ya que hasta ahora la autorización para el acceso a documentos clasificados no exigía una desclasificación completa por el órgano competente, sino que estos podían ser consultables "solicitando autorización a las administraciones que clasificaron la documentación o que la custodien". El acto de desclasificación formal resulta ahora preceptivo, con lo que ello supone de entorpecimiento a la labor investigadora y, dicho sea de paso, a la administrativa. Esto nos lleva a plantear la pregunta ¿quién y cómo decide qué son secretos oficiales de Estado y cuál es el régimen de acceso a los mismos?

La respuesta la hallamos en la Ley 9/1968, de 5 de abril, de Secretos Oficiales, modificada por la ley 48/1978, de 7 de octubre, así como en su Reglamento de desarrollo aprobado en 1969. ${ }^{31} \mathrm{La} \mathrm{LSO}$, una desconocida para la mayoría de historiadores porque hasta ahora apenas habíamos notado sus efectos, atribuye la capacidad para

30 Vid. Blanca DESANTES FERNÁNDEZ, "El proceso de acceso...", art. cit., nota 47.

31 Decreto 242/1969, de 20 de febrero, por el que se desarrollan las disposiciones de la ley 8/1968, de 5 de abril, sobre secretos oficiales. No entraremos aquí en el debate sobre la evidente conveniencia de sustituir una ley franquista y preconstitucional por una nueva norma más acorde con los principios de nuestra Carta Magna. Mientras distintos gobiernos han fracasado en sus intentos de impulsar una nueva norma sobre secretos oficiales, la jurisprudencia ha afirmado expresamente la conformidad de la LSO con la Constitución (Sentencia del 
calificar materias como secreto o reservado "exclusivamente, en la esfera de su competencia, al Consejo de Ministros y a la Junta de Jefes de Estado Mayor" (JUJEM) (art. 4) sin que esta facultad de calificación pueda ser transferida ni delegada (art. 5) ${ }^{32}$. A su vez, solo el órgano que hizo la respectiva declaración está facultado en cada caso para cancelar la clasificación (art. 7). El conocimiento de las materias clasificadas está reservado únicamente a las personas debidamente autorizadas, bajo formalidades y limitaciones muy estrictos definidos en la ley y el reglamento. Un importante caso específico de personal autorizado lo constituyen los diputados y senadores, dado que "la declaración de materias clasificadas no afectará al Congreso ni al Senado, que tendrán siempre acceso a cuanta información reclamen, en la forma que determinen los respectivos Reglamentos y, en su caso, en sesiones secretas" (art. 10.2). Una salvaguarda que busca garantizar el control parlamentario sobre la acción del gobierno y sobre el poder militar, extendiendo ese control incluso a las materias clasificadas.

Aunque se emplean con cierta laxitud términos como reservado, clasificado, secreto o confidencial, la LSO solo reconoce dos grados de restricción en las "materias clasificadas" que es el nombre oficial que, en consonancia con los usos internacionales, reciben "los asuntos, actos, documentos, informaciones, datos y objetos cuyo conocimiento por personas no autorizadas pueda dañar o poner en riesgo la seguridad y defensa del Estado" (art. 2 LSO). Estos dos grados son los "secreto" y "reservado" y se distinguen únicamente por el nivel de protección que se requiera. El Reglamento de la LSO prevé la clasificación de "secreto" para las materias

... que precisen el más alto grado de protección por su excepcional importancia y cuya revelación no autorizada por autoridad competente para ello, pueda dar lugar a riesgos o perjuicios de la seguridad del Estado, o pudiera comprometer los intereses fundamentales de la Nación en materia referente a la defensa nacional, la paz exterior o el orden constitucional.

La clasificación de "reservado" se aplicará en cambio a los asuntos, actos, documentos, informaciones, datos y objetos

... no comprendidos en el apartado anterior por su menor importancia, pero cuyo conocimiento o divulgación pudiera afectar a los referidos intereses fundamentales de la Nación, la seguridad del Estado, la defensa nacional, la paz exterior o el orden constitucional.

Ambas definiciones son suficientemente amplias como para cubrir un amplio abanico de materias, pero a la vez resultan excesivamente genéricas como para proporcionar un criterio operativo a los responsables de gestionar la documentación. Por eso es fundamental el artículo 10 de la LSO, que especifica que las clasificaciones de documentación "se conferirán mediante un acto formal" y con los requisitos y mate-

Tribunal de Conflictos Jurisdiccionales de 14 de diciembre de 1995 y Sentencia del Tribunal Supremo de 4 de abril de 1997 sobre los "papeles del CESID").

32 La norma original de 1968 todavía añadía una tercera instancia con capacidad para calificar documentación como secreto de Estado, concretamente los "Jefes de Misiones Diplomáticas de España en el extranjero" (art. 4.1), pero esta atribución fue eliminada con la reforma de 1978. 
rializaciones que establezca el reglamento correspondiente. Ahora bien, ¿cómo se ha concretado en nuestro país esta exigencia?

A tenor de la experiencia acumulada desde su promulgación, cabe suscribir el juicio de que la LSO "aunque vigente, nunca ha tenido un desarrollo e implantación adecuados en los diferentes Departamentos Ministeriales, excepto en el Ministerio de Defensa" ${ }^{33}$. Y ello a pesar de que el Reglamento de la LSO habilita, en una disposición adicional, tanto al Ministerio de Asuntos Exteriores como al de Defensa a elaborar normas específicas de régimen interior (en el caso de Exteriores, "para sus oficinas en el extranjero") en atención a las particularidades de las funciones del servicio diplomático y de las Fuerzas Armadas respectivamente. En la mayor parte de la administración, según el mismo experto, parece de aplicación esta reflexión: "una cosa es la clasificación de los documentos con arreglo a los procedimientos y normas referidos y otra, bien distinta, el límite 'por razón de estampilla', tan abundante como arbitrario en no pocos organismos públicos". Veamos brevemente el caso de Defensa y, con él, el del ministerio del Interior, para examinar después con algo más de detenimiento el caso de Exteriores. Observaremos cómo la tendencia apunta a que, con el paso de los años, el catálogo de materias clasificadas se ha ido incrementando, y con él las restricciones en el derecho de acceso a un número cada vez mayor de documentos.

En el ministerio de Defensa el temprano desarrollo normativo de la LSO se ha visto condicionado por la asunción por nuestro país de las diversas normas y grados que, en materia de información clasificada, existen en las organizaciones -en especial la OTAN- y países con los que España colabora en materia militar en virtud de tratados internacionales que, una vez publicados oficialmente en España, pasan a integrarse en nuestro ordenamiento jurídico. De este modo, mientras que para el conjunto del Estado, solo tiene vigencia, con arreglo a la LSO, la calificación de materias clasificadas como "secreto" y "reservado", el Ministerio de Defensa añade dos marcas de calificación más, las de "confidencial" y "difusión limitada", derivadas de los tratados internacionales. Estas dos marcas se aplican a las llamadas materias de reserva interna, aquellas cuya revelación no autorizada puede causar perjuicios a la seguridad e intereses del propio ministerio, y son de utilización exclusiva por Defensa en el ámbito de su competencia y en el de los tratados. ${ }^{34} \mathrm{El}$ ministerio del Interior por su parte aplica una única marca de reserva interna, la de documentación "confidencial" que, pese a no contar con el respaldo de la LSO, se entiende por el propio departamento como derivada de "la capacidad administrativa de limitar el acceso público a la documentación no clasificada, pero cuya información afecta a la Seguridad del Estado". Esta reserva resulta congruente, además, con denominaciones equivalentes empleadas en acuerdos internacionales suscritos por España con la OTAN, la UE

33 Daniel de OCAÑA LACAL, "'Ser o no ser'...", art. cit., p. 184 n. 79.

34 AUTORIDAD DELEGADA PARA LA SEGURIDAD DE LA DOCUMENTACIÓN CLASIFICADA, Oficina Nacional de Seguridad, "Orientaciones para la instrucción de seguridad del personal”, 15 de diciembre de 2009, http://www.cni.es/comun/recursos/descargas/OR-ASIP-02-02.02_Instruccion_de_Seguridad_del Personal_para_acceso_a_IC.pdf [consultado el 1/07/2012]. Véase también, del mismo organismo, la norma "NS/04 de Seguridad de la Información", octubre de 2009, http://www.cni.es/comun/recursos/descargas/NS04_Seguridad_de_la_Informacion.pdf [consultado el 1/07/2012]. 
y varios países, sobre intercambio de información clasificada o protegida, "a fin de otorgar a la información compartida de niveles de protección equivalentes a los del país de origen" 35 .

Dejando a un lado la reserva interna definida por ambos departamentos en sus normativas específicas ${ }^{36}$, cuya consulta tiene también normas propias ${ }^{37}$, examinaremos las materias clasificadas por actos formales del Consejo de Ministros. Hallamos en primer lugar un Acuerdo por el que se clasifican determinados asuntos y materias con arreglo a la Ley de Secretos Oficiales, aprobado por el Consejo de Ministros el 28 de noviembre de 1986 a propuesta de los ministros de Interior, Asuntos Exteriores y Defensa, que clasifica a materias de carácter militar como las deliberaciones de la Junta de Defensa Nacional y de la Junta de Jefes de Estado Mayor, el despliegue de unidades de los ejércitos o los estados de eficacia operativa y de moral de las unidades, entre otros asuntos. Posteriormente, el gobierno amplió por sendos Acuerdos de Consejo de Ministros de 17 de marzo y 29 de julio de 1994 el catálogo de materias clasificadas para extender el secreto sobre "las actuaciones de seguridad de vuelo" y "la adquisición y dotación de equipos de comunicaciones que se efectúen para la Casa Real" ${ }^{\prime 8}$. Y en febrero de 1996, en pleno proceso de revelaciones periodísticas y actuaciones judiciales por la "guerra sucia" de los Grupos Antiterroristas de Liberación (GAL) contra ETA, un gobierno técnicamente en funciones extendió, a propuesta del Ministerio de Justicia e Interior, la clasificación de secreto a "la estructura, organización, medios y técnicas operativas utilizadas en la lucha antiterrorista por las Fuerzas y Cuerpos de Seguridad del Estado, así como sus fuentes y cuantas informaciones o datos puedan revelarlas", y a "los ficheros automatizados que en materia antiterrorista establezca la Administración Penitenciaria" 39.

35 Según se indica en la nota 49 que comenta la Instrucción de la Secretaría de Estado de Seguridad de 14 de octubre de 1988, sobre normas de seguridad en el tratamiento de las materias clasificadas. El Ministerio del Interior otorga la clasificación de "confidencial" de manera genérica a "aquellos documentos que no recibiendo la de SECRETO o RESERVADO, merezcan a juicio del Jefe del órgano que los emite, un grado de protección superior al considerado de trámite ordinario”. La Instrucción se puede consultar en Rosana DE ANDRÉS DÍAZ y Luis CASADO DE OTAOLA (edición y recopilación), El sistema archivístico del Ministerio del Interior: normativa, Madrid, Ministerio del Interior, Secretaría General Técnica, $2^{\mathrm{a}}$ ed. corr. y aum., 2008 ( http://www.interior.gob.es/file/55/55771/55771.pdf, consultado el 1/07/2012)

36 La facultad para clasificar documentación como confidencial o de difusión limitada, en aplicación de la reserva interna, corresponde a los ministros, secretarios de Estado y subsecretarios en sus respectivos Departamentos, y a los Jefes de los Estados Mayores de la Defensa, Ejército, Armada y Aire, siempre que exista una normativa que regule el uso de estos dos grados de clasificación. Vid. norma la "NS/04 de Seguridad de la Información", octubre de 2009, citada.

37 Normas que deben adecuarse en todo caso al art. 27.2. del RDSEA 1708/2011: "Cuando la solicitud de consulta se refiera a documentos o series documentales que incorporen marcas de reserva o confidencialidad, el órgano competente para resolver remitirá la solicitud a su superior jerárquico o, según lo que establezcan las normas de organización de los respectivos Departamentos Ministeriales y entidades de Derecho Público, al órgano que realizó la declaración de reserva o confidencialidad, para que decidan sobre la concesión de autorización de la consulta."

38 Acuerdo del Consejo de Ministros, de 28 de noviembre de 1986, por el que se clasifican determinados asuntos y materias con arreglo a la Ley de Secretos Oficiales, ampliado por Acuerdos de Consejo de Ministros de 17 de marzo y 29 de julio de 1994.

39 Acuerdo del Consejo de Ministros de 16 de febrero de 1996, por el que se clasifican determinados asuntos y materias con arreglo a la Ley de Secretos Oficiales. Aunque el acuerdo previo de 1986 ya incluía la calificación de secreto para la estructura, organización, medios y procedimientos operativos específicos de 
Hasta aquí, puede aceptarse con más o menos matices que se había actuado a lo previsto en la LSO en cuanto a la protección de materias que afectan directamente a la seguridad nacional y la defensa del Estado. Pero en 2010 se produjo un salto cualitativo que afecta directamente a los historiadores -aunque no solo a ellos-, cuando el Consejo de Ministros aprobó el 15 de octubre por iniciativa del titular de Exteriores, Miguel Ángel Moratinos, el Acuerdo sobre politica de seguridad de la información del Ministerio de Asuntos Exteriores y de Cooperación por el que se clasifican determinadas materias con arreglo a la Ley de Secretos Oficiales ${ }^{40}$. No está de más recordar que el acuerdo se aprobó en un momento en que la organización Wikileaks había publicado decenas de miles de documentos oficiales estadounidenses sobre la guerra de Afganistán y anunciaba para el otoño de 2010 nuevas filtraciones -incluyendo cablegramas diplomáticos- que afectarían a Estados Unidos y sus aliados. El propio ministerio de Exteriores español había sufrido en tiempos recientes, por su parte, algunas fugas y pérdidas de información que cuestionaban la eficaz custodia de las materias más sensibles por parte de la diplomacia española ${ }^{41}$. Si el acuerdo de 2010 pretende ser una respuesta a ambas situaciones es algo sobre lo que no tenemos una explicación oficial. En cualquier caso el texto permite al gobierno blindar la práctica totalidad de la documentación diplomática, al clasificar como secreto catorce materias, que incluyen:

1-Posiciones básicas de España y estrategias en negociaciones políticas, de seguridad, económicas y comerciales que conciernan a los intereses esenciales del Estado tanto en el ámbito bilateral como en la Unión Europea, la Organización del Tratado del Atlántico Norte, el sistema de Naciones Unidas, la Conferencia Iberoamericana u otras Organizaciones y Conferencias Internacionales.

los servicios de información, así como sus fuentes y cuantas informaciones o datos pudieran relevarlas, el gobierno consideró necesario "clasificar expresamente como secretos los procedimientos, medios y técnicas operativas utilizadas en materia antiterrorista por las Fuerzas y Cuerpos de Seguridad del Estado".

$40 \mathrm{El}$ texto completo puede verse en http://ep00.epimg.net/descargables/2012/06/03/81b3c3748773b522e 38eb34079877132.pdf [consultado el 1/07/2012]. Al día siguiente de su publicación en la prensa, el ministro de Exteriores, José Manuel García-Margallo, anunció una revisión del acuerdo que, en el momento en que se escriben estas líneas, no se ha producido. Véase El País, 5.06.2012: "Exteriores revisará el acuerdo que declara secretos todos sus documentos",

41 En diciembre de 2008 se reveló que el informe original de 11 de enero de 2002, que recogía la autorización del gobierno español, presidido por José María Aznar, para que los vuelos de la CIA a Guantánamo con prisioneros de al-Qaeda hicieran escala en España, había desaparecido sin que pudiera localizarse ni en el Archivo Central del Ministerio de Asuntos de Exteriores, ni en el archivo del director general de Política Exterior para América del Norte ni en los del secretario de Estado (Miguel GONZÁLEZ, El País, 17 .12.2008, "El redactor del informe secreto dice que ni lo destruyó ni lo mandó destruir"). Ese mismo mes, el ministro Miguel Ángel Moratinos anunciaba una reforma de la gestión y custodia de los documentos internos de su departamento, tras conocerse la filtración de un informe reservado por parte de un cónsul español en Brasil (La Razón, 19.12.2008, "Reforma de los secretos oficiales"). Los problemas de control de la información no eran, sin embargo, privativos de Exteriores: en febrero de 2010 era condenado por traición el ex agente del Centro Nacional de Inteligencia Roberto Flórez, culpable según la sentencia de filtrar a una potencia extranjera documentación secreta y susceptible de perjudicar la seguridad nacional, incluyendo la lista de siete espías españoles que resultaron asesinados en Iraq el 29 de noviembre de 2003 (El Mundo, 11.02.2010, "El ex espía del CNI Flórez, primer condenado por traición de la democracia"). 
2-Información sobre posiciones españolas en conflictos internacionales o internos de naturaleza política, social, económica o comercial que puedan comprometer los intereses españoles o su capacidad de interlocución con terceros países.

3-Información relativa a la actuación de grupos terroristas y movimientos a ellos asociados, delincuencia organizada y tráfico de drogas, personas y armas con implicaciones o ramificaciones en España o en los países con los que España haya suscrito acuerdos sobre dichas materias o mantenga relaciones de amistad.

4-Información relativa al despliegue de unidades de las Fuerzas Armadas y Fuerzas y Cuerpos de Seguridad del Estado españolas y aliadas tanto en España como en misiones internacionales.

5-Negociaciones y buenos oficios sobre secuestros y liberación de ciudadanos españoles o extranjeros así como la información relativa a las extradiciones o traslado de personas condenadas.

6-Contactos de mediación o buenos oficios llevados a cabo por España con terceros países y con grupos y líderes de oposición para facilitar procesos de paz y la promoción o defensa de los derechos humanos.

7-Protección de Derechos Humanos, con especial incidencia en casos humanitarios especialmente sensibles y las gestiones con terceros países en este ámbito.

8-Cuestiones de asilo y refugio.

9- Tramitación de beneplácitos de Jefes de Misión españoles y extranjeros.

10- Información relativa a cuestiones que afecten a la soberanía, independencia y a la integridad territorial de España o de países amigos y a las posiciones de España sobre contenciosos de índole territorial inter-estatales o intra-estatales.

11- Informaciones relativas a la aplicación de Acuerdos bilaterales o multilaterales sobre asuntos de seguridad y defensa suscritos por España, incluidas aquellas relacionadas con sobrevuelos, estancias y escalas de buques y aeronaves.

12- Asuntos relacionados con los crímenes más graves de trascendencia internacional sobre los que pueda tener jurisdicción la Corte Penal Internacional u otros Tribunales Internacionales y aquellos sometidos ante Tribunales españoles.

13- La información relativa a los preparativos de los viajes de SS.MM. los Reyes y del Presidente del Gobierno y, cuando las circunstancias lo aconsejen, de los Ministros y otras autoridades del Estado.

14- Las claves y material criptográfico.

Un segundo apartado del mismo acuerdo otorgaba la clasificación de reservado a las materias, "así como los actos, documentos, informaciones, datos y objetos sobre las mismas" cuya "revelación no autorizada pueda dañar o poner en riesgo la seguridad y defensa de España o sus aliados y amigos, los intereses políticos, sociales, económicos y comerciales y las relaciones diplomáticas con terceros países", y específicamente a: 
1-Entrevistas con mandatarios o diplomáticos extranjeros con implicaciones para los intereses del Estado o las relaciones internacionales.

2-Gestiones de apoyo en las licitaciones de empresas españolas en el exterior $\mathrm{y}$ en contenciosos de especial gravedad que les afecten.

3-Candidaturas españolas a puestos en organismos internacionales.

El acuerdo todavía extiende más las restricciones, al establecer: "Tendrá [sic] la misma clasificación genérica de secreto o reservado, según corresponda, todos aquellos documentos necesarios para el planteamiento, preparación o ejecución de los documentos, acuerdos o convenios a que se refieren los apartados anteriores así como la documentación que los remita, comente o evoque". Esta lista de materias, por último, "será objeto de actualización periódica", según se especifica, lo que abre el camino a posteriores ampliaciones de la clasificación de documentos.

La aplicación de este acuerdo en conjunción con lo previsto en la LSO y, posteriormente, también en el en el RDSEA 1708/2011, por parte de la Secretaría General Técnica -responsable del Archivo General de Exteriores- ha creado desde el otoño de 2011 una situación muy complicada para los historiadores que pretendían consultar la documentación diplomática española. Fondos y temáticas enteras relativas a las relaciones internacionales de España durante la transición democrática, el franquismo, la guerra civil y aún periodos anteriores han quedado vedados al acceso público, como han comunicado a quienes solicitaban consultarlos los responsables del archivo, al comienzo de manera puramente verbal y desde abril de 2012 por escrito mediante la preceptiva resolución administrativa. ${ }^{42}$

El giro involutivo del Archivo General de Exteriores es tanto más incomprensible cuanto que este ministerio podía presumir desde los años ochenta de aplicar una de las normativas de acceso a la documentación diplomática más liberales del mundo, sin que por ello se hayan dañado la seguridad y defensa del Estado, al menos no como resultado de la labor de los cientos de historiadores e investigadores que han pasado por sus salas desde entonces. Fue la Orden Ministerial de 18 de enero de 1984, la que situó al Archivo General del MAE a la vanguardia del aperturismo, al permitir la consulta de todos sus fondos una vez transcurridos veinticinco años desde la fecha de producción de los documentos. Este plazo era realmente excepcional y muy avanzado, tanto en su momento como en comparación con los parámetros actuales, dado que en los archivos diplomáticos internacionales la regla general suele ser de treinta años de reserva. La norma adoptada por Exteriores especificaba únicamente dos excepciones en el acceso público: el de los documentos que expresamente estuvieran declarados como "materia reservada" con arreglo a la LSO, y aquellos "de carácter

42 Entre tanto los medios de comunicación y algunos especialistas se han hecho eco de los problemas que están encontrando los investigadores para acceder a la documentación diplomática de carácter histórico, así como en general del secretismo generalizado que el Ministerio de Asuntos Exteriores y de Cooperación ha extendido sobre su documentación. Véase Miguel GONZÁLEZ, "Exteriores blinda todos sus documentos", El País, 4.06.2012; Katya CASCANTE, "Los secretos de Exteriores”, El País, 8.06.2012, y la nota de la Comisión Española de Historia de las Relaciones Internacionales "El archivo del Ministerio de Asuntos Exteriores y los problemas para la investigación y los historiadores", 6 de junio de 2012, http://www.ucm.es/info/ hcontemp/documentos/NotaCEHRIMAEC.pdf [consultado el 1/07/2012] 
personal, así calificados en su título, mientras las personas a que se refieran, sigan en vida”. El criterio liberalizador así adoptado resultaba tanto más relevante, cuanto que afectaba a documentación oficial que en principio se relacionaba directamente con la defensa del interés del Estado. También en lo relativo a la documentación que contuviera datos de carácter personal se aplicaba un patrón mucho menos restrictivo que el que consagraron las leyes y normas que vendrían después, ya que para considerar un documento como no consultable, el título del mismo debía especificar ese carácter de documentación personal, lo que en principio restringía el volumen de documentación así protegida. ${ }^{43}$

La orientación aperturista se mantuvo cuando el Ministerio adaptó el acceso a sus archivos al marco creado por la LPHE de 1985, por medio de la Orden Ministerial de 2 de abril de 1991, hoy vigente. La nueva normativa también establecía, en su apartado $4^{\circ}$, que "será de libre consulta la documentación depositada en los Archivos indicados (el Archivo General del Ministerio y el AGA, sección $\mathrm{M}^{\mathrm{o}}$ Exteriores)". Claro está, establecía excepciones, particularmente de los documentos que: "a) No deban ser públicamente conocidos por disposición expresa de la ley. b) Afecten a materias clasificadas de acuerdo con la Ley. c) Puedan entrañar riesgos para la seguridad y la defensa del Estado o la averiguación de los delitos, en caso de difundirse su contenido" "44. Añadía, para el caso de los documentos que no debían ser conocidos públicamente por disposición expresa de la Ley, que "podrán ser consultados en los plazos y con los requisitos establecidos en la misma". Pero lo más importante era el punto 2 del apartado $5^{\circ}$, que establecía un plazo fijo para las limitaciones de acceso a las materias clasificadas y a los documentos que pudieran entrañar riesgos a la seguridad y defensa del Estado:

2. Los fondos documentales del Archivo General del Departamento incluidos en los apartados b) y c) de la norma anterior, podrán ser objeto de consulta cuando haya transcurrido el plazo fijado al efecto por la Autoridad que efectuó la clasificación o calificación, o al cabo de veinticinco años desde la fecha de los documentos, respectivamente. También podrán ser consultados antes de que transcurran dichos plazos si lo autoriza expresamente la autoridad que hizo la clasificación o calificación, o el secretario General Técnico del Departamento en los casos restantes.

Es decir, la norma establecía, de hecho y al igual que su antecesora, un plazo de veinticinco años para poder consultar toda aquella documentación clasificada procedente del Ministerio de Asuntos Exteriores. Esto colocaba a los archivos diplomáticos españoles, en teoría, en un puesto destacado en cuanto a transparencia y facilidades de acceso. ${ }^{45}$

43 Orden Ministerial de 18 de enero de 1984 por el que se autoriza la consulta de documentos con fines de investigación en el Archivo General y Biblioteca del Ministerio de Asuntos Exteriores, BOE de 18 de febrero de 1984.

44 La Orden Ministerial añadía un apartado d) para los documentos que contengan datos personales expresamente protegidos por la Ley de Patrimonio Histórico Español, reproduciendo las limitaciones y condiciones de acceso en ella establecidas.

45 Sobre este archivo véase SANTOS CANALEJO, Elisa Carolina de: Guía del Archivo General del Ministerio de Asuntos Exteriores. Ministerio de Asuntos Exteriores, Secretaría General Técnica, 1997. 
Apenas merece la pena subrayar el enorme retroceso que supone el giro restrictivo aplicado por Exteriores desde 2011, pero sí querríamos destacar una serie de problemas que plantean el acuerdo de Consejo de Ministros de 2010 y la interpretación que se ha optado por darle en este archivo. Para comenzar, no es un dato secundario el hecho de que el acuerdo no se publicara en el Boletín Oficial del Estado, ni tampoco apareciera en la referencia del Consejo de Ministros que se hace pública en la página web del Ministerio de la Presidencia del Gobierno. Según afirmó posteriormente el titular de Exteriores, el acuerdo mismo era secreto y tuvo que ser desclasificado por el Consejo de Ministros para poder ser comunicado cuando fue reclamado por uno de los firmantes de este artículo. ${ }^{46} \mathrm{Su}$ contenido no se hizo público, de hecho, hasta el 9 de mayo de 2012, diecinueve meses después de su entrada en vigor. ${ }^{47}$ Cabe preguntarse cómo es posible que en un Estado de derecho el gobierno restrinja un derecho como el de acceso a la documentación sin dar publicidad a la norma que así lo establece. Del mismo modo, la clasificación de materias tan amplias como las contempladas en el acuerdo de 2010 convierte de la noche a la mañana a innumerables periodistas, investigadores, especialistas de los más diversos ámbitos e historiadores de la contemporaneidad más reciente en conocedores involuntarios de secretos de Estado, instalándolos en una palmaria inseguridad jurídica. ${ }^{48}$ No está de más recordar a este respecto que la revelación de secretos oficiales es un delito que las leyes españolas castigan severamente.

En segundo lugar, el principal problema que plantea el acuerdo de 2010 estriba en la extensión que realiza sobre las materias clasificadas, que van mucho más allá de lo previsto en la LSO. Donde ésta limita lo susceptible de ser materia clasificada a lo que "pueda dañar o poner en riesgo la seguridad del Estado o comprometa los intereses fundamentales de la Nación en materia referente a la defensa nacional, la paz exterior o el orden constitucional", el acuerdo de 2010 clasifica como secreto las materias cuya revelación no autorizada "pueda dañar o poner gravemente en riesgo la seguridad y defensa de España o de sus aliados o amigos, así como los intereses políticos, sociales económicos y comerciales y las relaciones diplomáticas con terceros países". Cabe realizar tres comentarios. Por una parte, por lo que respecta a los "aliados o amigos de España”, el Reglamento de 1969 establece que la Administración debe proteger la información de naturaleza reservada suministrada a España por países extranjeros o por organizaciones internacionales, otorgándoles una clasificación que garantice un grado protección igual o mayor que el requerido por el gobierno u organización que suministró la información. Igualmente, España tiene suscritos di-

46 Miguel GONZÁLEZ, "Exteriores revisará el acuerdo que declara secretos todos sus documentos", El País, 5.06.2012.

47 Comunicación de la Secretaria General Técnica del MAEC a Carlos Sanz de 9 de mayo de 2012.

48 La LSO establece que si una persona llega a conocimiento o posesión de cualquier materia clasificada, y le consta esta condición, debe mantenerla en secreto y "entregarla a la autoridad civil o militar más cercana y, si ello no fuese posible, a poner en conocimiento de ésta su descubrimiento o hallazgo" para que ésa la comunique "sin dilación al departamento ministerial que estime interesado o a la Presidencia del Gobierno, adoptando entretanto las medidas de protección que su buen juicio le aconseje”. La excepcionalidad que estas medidas indican confirman indirectamente la idea de que una enumeración de materias clasificadas tan amplia y general como la que contiene el acuerdo de C.M. de 15 de octubre de 2010 no se adecúa a lo previsto en la LSO. 
versos acuerdos bilaterales sobre protección mutua de información clasificada, aparte de las obligaciones contraídas en esta materia por su participación en organizaciones internacionales. ${ }^{49}$ Ahora bien, mientras el reglamento de la LSO, por ejemplo, se refiere a documentos clasificados en origen por otro país u organización, el acuerdo de 2010 prescinde en cambio de este requisito y se aplica también a documentación española, que puede ocultarse alegando un posible riesgo para aliados o amigos, cuya naturaleza e intensidad corresponde interpretar en todo caso al Ejecutivo. Con ello refuerza la tendencia al secretismo y se amparan prácticas como la del gobierno español que, en marzo de 2006, se negó a proporcionar información oficial sobre la participación de la fragata Álvaro de Bazán en acciones de guerra en aguas del Golfo Pérsico, alegando que esta información contenía "información táctica, operacional y estratégica sensible para los intereses de Estados Unidos". ${ }^{50}$

Por otra parte, el extenso listado de materias incluido en el acuerdo de 2010 vulnera lo que el sentido común y el propio espíritu y la letra de la LSO y de nuestro ordenamiento constitucional permiten afirmar, es decir, que lo secreto debe ser la excepción, y no la norma, ya que prima el principio de publicidad de la actuación de los órganos públicos. ${ }^{51} \mathrm{El}$ catálogo de prohibiciones aprobado en 2010 invierte este principio y blinda con el manto del secretismo prácticamente toda la actividad relativa a la política exterior del Estado, hasta los asuntos más triviales. Así lo acredita el hecho de que se haya denegado el acceso a cuestiones tan inocuas como las relaciones entre España y Filipinas entre 1975 y 1982 o entre España y la República Democrática Alemana (un Estado, por cierto, que dejó de existir hace 22 años) entre 1970 y 1986, de cuya investigación histórica no cabe esperar razonablemente ninguna lesión para la seguridad y la defensa del Estado español actual. Ni siquiera con la extensión cada vez mayor del concepto de seguridad, que es explícita en documentos como la Estrategia Española de Seguridad aprobada en 2011 por el gobierno español, cabe excluir del examen público un abanico tan amplio de materias como el que cubre el acuerdo

49 Concretamente con Estados Unidos, Noruega, Grecia, Israel, Suiza, Suecia, Bulgaria, Estonia, Polonia, Francia, Letonia, Italia, Alemania y Eslovaquia. El listado de estos acuerdos puede consultarse en la página web de la Oficina Nacional de Seguridad, http://www.intelpage.info/oficina-nacional-de-seguridad-ons6.html

50 En su respuesta escrita al diputado Arsenio Fernández de Mesa, que reclamaba la información, el gobierno reconocía que parte de esa información no quedaba cubierta por la LSO, pero se acogía al acuerdo "sobre seguridad de información militar clasificada" suscrito por España y Estados Unidos en 1984 para denegar el acceso tanto a documentos clasificados estadounidenses como a documentación española que incorporaba "información clasificada obtenida de fuentes estadounidenses". Se daba la circunstancia de que la misión en que participó este navío quedó documentada parcialmente “en las crónicas que la propia Marina de Estados Unidos ha(bía) ido publicando en su web oficial”, según informó El Mundo, 28.03.2006: "El gobierno niega al PP los datos que pidió sobre la fragata 'Álvaro de Bazán”.

51 No merece la pena insistir en el hecho de que el art. 20.1.d. de la CE de 1978 reconoce expresamente el derecho "a comunicar o recibir libremente información veraz por cualquier medio de difusión”. La propia LSO afirma en su exposición de motivos que "las cosas públicas que a todos interesan pueden y deben ser conocidas de todos" y anuncia "normas severas que impidan la generalización de calificaciones que tienen carácter excepcional". El art. 3.IV del reglamento de la LSO estipula la creación de "procedimientos para determinar, periódicamente, la conveniencia de la reclasificación o desclasificación" del material calificado a fin de evitar su "acumulación excesiva". 
de $2010 .{ }^{52}$ En cualquier caso, la protección de los intereses sociales, económicos y comerciales del país no está prevista en la legislación y es dudosa su aplicación.

En tercer lugar, cabe afirmar que, si el texto del acuerdo deja que desear, aún más problemática es la lectura y aplicación que del mismo se ha hecho en el Archivo General del MAEC, que es donde la actividad de los investigadores se ha visto directamente afectada. Parte de los obstáculos son atribuibles a las mismas malas prácticas en la aplicación de las normas apuntadas en el apartado anterior. Se ha denegado la consulta de series completas, sin individualizar qué documentos o expedientes podían contener información sensible y cuáles no. Esto no es congruente con la legislación vigente: no pueden declararse reservadas materias generales, sino únicamente datos o documentos concretos, que además deben identificarse claramente -normalmente con un tampón o estampilla. Por supuesto, mucho menos se ha diferenciado entre partes de un mismo documento cuya información podía ser comunicable de aquellas otras que debían permanecer ocultas. Tampoco parecen suficientes, a nuestro parecer, las motivaciones de las resoluciones denegatorias por la Secretaría General Técnica, que se apoyan en decisiones de la Dirección General o instancia superior más próxima a la materia solicitada, y que se comunican a los investigadores en términos totalmente genéricos ${ }^{53}$ En lugar de proceder a un examen detallado de la documentación y a la separación de lo que efectivamente sea "secreto" o "reservado" y lo que no, se bloquea el acceso a la misma en su conjunto. ${ }^{54}$

Por otra parte, se ha aplicado el acuerdo con carácter retroactivo, entendiendo que sus efectos se extendían sin límite temporal fijo, lo que ha llevado a denegar documentación histórica incluso a los mismos investigadores que la habían consultado anteriormente. ${ }^{55}$ En realidad, las denegaciones de acceso comunicadas por la Secretaría General Técnica del MAEC no especifican ningún plazo pasado el cual la documentación pasaría a ser consultable. Ello, a pesar de que el reglamento de la LSO establece (art. 3.II) que, siempre que sea posible, debe indicarse el plazo de duración de la

52 La determinación de lo que supone una amenaza a la "seguridad y defensa del Estado" se ha ido ampliando en las últimas décadas en todos los países, al pasarse de una concepción de la defensa basada en lo puramente militar a visiones más holísticas. En la Estrategia Española de Seguridad de 2011, por ejemplo, se incluye como principales "amenazas y riesgos" a la seguridad los conflictos armados, el terrorismo, el crimen organizado, la inseguridad económica y financiera, la vulnerabilidad energética, la proliferación de armas de destrucción masiva, las ciberamenazas, los flujos migratorios no controlados, y las emergencias y catástrofes. GOBIERNO DE ESPAÑA, Estrategia Española de Seguridad. Una responsabilidad de todos, Madrid, BOE, 2011. Consultable en http://www.lamoncloa.gob.es/NR/rdonlyres/D0D9A8EB-17D0-45A5ADFF-46A8AF4C2931/0/EstrategiaEspanolaDeSeguridad.pdf

53 Por ejemplo, una resolución denegatoria de la SGT sobre acceso a la documentación del MAE comunicada el 10 de abril de 2012 se apoyaba en que, según informe de la D.G. de Relaciones Bilaterales con Países de la Unión Europea, Países Candidatos y Países del Espacio Económico Europeo de 16 de marzo de 2012, “(...) la documentación relativa a las relaciones políticas de España con la República Federal de Alemania y la República Democrática Alemana entre 1970 y 1982 cae dentro de los supuestos contemplados en el apartado primero del Acuerdo del Consejo de Ministros, de 15 de octubre de 2010, por lo que el criterio en el asunto de referencia es negativo".

54 No está de más recordar que las materias y documentos clasificados deben estar claramente identificados, con especificación de la clasificación que les corresponde (art. 10.4 LSO).

55 Durante meses, las denegaciones verbales de consulta en la Sala de Lectura del Archivo General del MAEC afectaron solo a la documentación posterior a 1967, contando con la entrada en vigor de la LSO en 1968. Posteriormente este criterio se abandonó y pasó a denegarse el acceso a documentación anterior. 
clasificación, así como la mención de si pudiera ser suprimida o rebajada de grado. ${ }^{56}$ Y a pesar también de lo que figura en la ya citada Recomendación $n^{\circ} \mathrm{R}(2000) 13$ del Comité de Ministros del Consejo de Europa sobre una política europea en materia de comunicación de los archivos (adoptada el 13 de julio del 2000), "III.7.2. Toda clasificación más allá del plazo general [de protección] debe imponerse por un periodo determinado, al término del cual debe realizarse efectivamente la desclasificación". Mientras que en otros países la desclasificación y publicación de los documentos diplomáticos y del conjunto de la Administración es un acto automático y rutinario, que se produce con exactitud matemática según se cumplen los plazos de cautela, en España lamentablemente o no se produce u obedece a reglas y criterios inaccesibles para el ciudadano. ${ }^{57}$

En este caso no solo no se han especificado plazos claros, sino que una norma que parece más apropiada para archivos de gestión o intermedios, y para expedientes abiertos (o que afectan a materias actuales o muy recientes), se ha aplicado a un archivo histórico y a documentación que por razón de su antigüedad y por referirse a procesos ya cerrados no cabe sino conceptuar como también histórica. ${ }^{58}$ Una vez más, se observa el retroceso (avalado por el RDSEA 1708/2011) respecto a la regla de acceso automático a los documentos de más de veinticinco años de antigüedad hasta ahora vigente en el Archivo General del MAEC, que parecía ofrecer suficientes garantías tanto al Estado y la Administración como a los ciudadanos en su derecho de acceso a la información.

A falta de plazos claros, podría servir como orientación la ya citada STC 43/2004, de 23 de marzo, que aunque se refiere a la protección del derecho a la intimidad y el honor, ofrece un criterio aplicable a los intereses y relaciones internacionales del Estado: no es lo mismo la documentación muy reciente que la más antigua, cuya "peligrosidad" potencial se ha diluido necesariamente con el paso del tiempo. La cautela en el acceso a la documentación debería ir cediendo con el paso del tiempo a la primacía del derecho a investigar los hechos del pasado, único criterio que permite

56 Esta redacción del reglamento parece abrir la posibilidad de articular un mecanismo de solicitud de desclasificación de documentos públicos similar a los que existen en otros países, pero del que carece España. No es la única cortapisa a la hora de solicitar, por parte de los ciudadanos, el acceso a documentación clasifica: la simple imposibilidad de conocer la existencia de esta documentación ya es obstáculo suficiente en la mayoría de los casos. Y eso que el RDSEA 1708/2011 establece (art. 26.2) que "El responsable del archivo, siempre que sea posible, tendrá a disposición del público la relación de los documentos y series documentales de acceso restringido, con exclusión de aquellos que en atención a los intereses protegidos no deban ser objeto de publicidad."

57 Eso, cuando no ocurre que, por criterios políticos, se bloquean desclasificaciones ya previstas, como ha hecho recientemente el ministro de Defensa Pedro Morenés al detener la publicación de 10.000 documentos de este departamento de entre 1939 y 1968 que su antecesora, Carme Chacón, había dejado listos para su apertura al público. Aunque parezca increíble, el ministro ha aducido que la información contenida en estos documentos, de entre 73 y 44 años de antigüedad, podía perjudicar las relaciones diplomáticas españolas. El País, 29.05.2012, "Defensa aparca la desclasificación de 10.000 expedientes secretos".

58 No se nos escapa el problema que plantea el hecho de que el Archivo General del MAEC sea a la vez archivo histórico y archivo intermedio. Ello no debería impedir reconocer el hecho de que gran parte de la documentación que custodia es histórica. Tampoco cabe defender, como a veces se ha afirmado, que "en política exterior los expedientes no se cierran nunca". Una cosa es la actualidad de un litigio que puede hundir sus raíces en siglos de historia y otra impedir la investigación histórica sobre los mismos, pasado un tiempo prudencial. 
salvaguardar el principio general de transparencia y la libertad de información e investigación. Tanto más cuanto que ya existen antecedentes en que se ha obtenido, mediante el recurso a los tribunales, acceder a documentos que el Archivo del Ministerio de Asuntos Exteriores pretendía denegar. En efecto, en 1999 la Audiencia Nacional dictó sentencia sobre una demanda interpuesta por un investigador alemán a quien se había impedido acceder a documentos de este archivo con más de 50 años relativos a la repatriación de nazis desde España durante la posguerra mundial ${ }^{59}$. ¿Será necesario recurrir a la vía judicial para poder investigar las relaciones internacionales históricas de España, o se impondrá el sentido común y Exteriores aplicará criterios más razonables de consulta de su documentación?

Excedería de nuestro propósito indicar cómo podría darse solución a la situación aquí descrita, pero no nos resistimos a señalar que, aparte del plano normativo, existe la posibilidad de aprovechar los desarrollos administrativos previstos en la legislación para garantizar un acceso más transparente a la documentación de Exteriores. Mencionaremos dos ejemplos solamente. Por una parte, el RD 1708/2011 prevé en su disposición adicional quinta que el ministerio de Asuntos Exteriores y de Cooperación pueda crear un sistema archivístico propio, lo que podrá hacerse mediante Real Decreto de iniciativa conjunta de este departamento y del Ministerio de Cultura, para dar un tratamiento adecuado "a la documentación que afecta a las relaciones internacionales de España" (disposición adicional quinta). ${ }^{60}$ Por otra parte, podría volver a constituirse la Comisión Calificadora de Fondos Documentales del MAEC, creada en 1991 y suprimida en $2011,{ }^{61}$ y encomendarle tareas efectivas de clasificación y desclasificación de documentación. Claro está, todo ello será siempre insuficiente si no se dota al Archivo General del MAEC de los imprescindibles medios humanos y materiales que requieren la correcta descripción, catalogación y comunicación del que es uno de los archivos diplomáticos más ricos del mundo.

En lugar de recurrir a estas u otras posibilidades igualmente factibles, los responsables del Ministerio de Asuntos Exteriores han optado finalmente, no por resolver el problema, sino por deshacerse lisa y llanamente de él, trasladando sus fondos archivísticos a otros departamentos. En efecto, el 20 de julio de 2012 la Secretaría General técnica comunicaba a los investigadores que el MAEC había acordado con el Ministerio de Educación, Ciencia y Deporte transferir sus fondos documentales a los archivos correspondientes del Sistema de Archivos de la Administración General del Estado, "principalmente, el Archivo Histórico Nacional y el Archivo General de la Administración". Como consecuencia de las labores preparatorias necesarias para

\footnotetext{
59 Audiencia Nacional, Sala de lo Contencioso-administrativo, Sección Cuarta, Sentencia recurso 880/97. Vid. El País de 11.07.1999, "La audiencia obliga a Exteriores a abrir sus archivos sobre los nazis".

60 Se situaría así en una situación similar a la de los archivos de la Defensa y los de Interior. Los archivos militares han contado desde el siglo XIX con una organización propia e independiente de los de la Administración civil del Estado. El ministerio de Interior también cuenta con un sistema archivístico propio y además tiene constituida desde el año 2000 su correspondiente Comisión Calificadora de Documentos Administrativos.

61 La Comisión Calificadora de Fondos Documentales del Ministerio de Asuntos Exteriores y de Cooperación, que creó la Orden Ministerial de 2 de abril de 1991, fue suprimida por el Real Decreto 776/2011, de 3 de junio por el que se suprimen determinados órganos colegiados..., sin que en veinte años de existencia sobre el papel se le conozca actividad alguna ni exista constancia pública de que llegara a constituirse efectivamente.
} 
esta transferencia, desde el 15 de septiembre de 2012 los usuarios ya no pueden consultar la documentación en la sala de lectura del Archivo General del MAEC.

Los investigadores esperamos que la mejora de las condiciones de accesibilidad que la SGT esgrime como justificación para tan drástica medida compense los trastornos ocasionados a numerosas investigaciones en curso, proyectos y tesis doctorales con el bloqueo temporal de la documentación y la incertidumbre sobre el plazo en que los fondos volverán a estar disponibles en los archivos de destino.

\section{Conclusiones}

Como hemos visto, en la legislación inicial sobre acceso a los archivos públicos, tanto históricos como administrativos, la regla general era el libre acceso, y las restricciones unas excepciones justificadas. Como toda limitación a un derecho fundamental, estas excepciones deberían ser interpretadas siempre restrictivamente, y no de forma extensa o desmedida. En la práctica, sin embargo, la extensión continua de las restricciones que se fundan en la protección de la intimidad de las personas o en la salvaguardia de la seguridad del Estado han arrinconando el derecho de acceso a una posición irrelevante y marginal. Leyes incoherentes entre sí, indefiniciones y ambigüedades, están dificultando gravemente la investigación científica que se apoya en fuentes documentales custodiadas en los archivos públicos. Esto es algo que ha sido recurrentemente señalado por la literatura jurídica que aborda estas cuestiones. Por ello, merece la pena plantearse la necesidad de mejorar las leyes que tratan de estos asuntos o, mejor aún, regular expresamente el derecho de acceso a los registros y archivos públicos que está enunciado en la Constitución Española pero nunca ha sido desarrollado. Mientras que la protección de datos personales cuenta con una ley orgánica, ampliamente desarrollada en reglamentos contundentes e invasivos, y sobre todo cuenta con una Agencia estatal que vigila su cumplimiento, auténtico brazo armado del fundamentalismo protector de la intimidad, el derecho de acceso está pobremente regulado en normas dispersas y no cuenta con ninguna instancia que vele por su respeto ${ }^{62}$. Hace falta una nueva regulación del derecho de acceso a los documentos y archivos públicos que frene el carácter invasivo y hermético del sistema de protección de datos personales y el retroceso proteccionista en la salvaguardia de secretos oficiales.

En vista de la experiencia pasada, nos atrevemos a sugerir algunos principios en los que debería basarse la nueva legislación de acceso. El primero es que los criterios para declarar una documentación como "histórica" no se basen en el tipo de archivo que la custodia, sino en la pérdida de vigencia administrativa y en la antigüedad; en

62 En Francia cumple esta misión la Commission d'Access aux documents administratives (CADA), eficaz contrapeso a la Commission Nationale de l'Informatique et des Libertés (CNIL), que se encarga de la protección de datos. En los EE.UU la Freedom of Information Act establece todo un sistema de garantías para el acceso de los ciudadanos a los datos públicos. En cada organismo del poder ejecutivo hay una oficina especialmente dedicada a garantizar ese derecho, y a ella se puede dirigir cualquier ciudadano para pedir amparo. Además, cualquier persona -americana o no- puede reclamar la desclasificación de un documento que permanezca secreto, y la administración debe argumentar y demostrar que no está obligada a hacerlo. 
otros países se considera histórica toda aquella documentación con más de 25 años de antigüedad. También sería necesario distinguir entre acceso, tratamiento automatizado, consulta y difusión de los datos contenidos en los documentos. Creemos que se podría regular la utilización responsable de los datos por parte de los investigadores mediante declaración expresa de respeto a la confidencialidad, y de no usarlos de forma que puedan afectar al ámbito privado de las personas. En algunos archivos -en el Archivo Histórico Nacional así se hacía- se pide al investigador el compromiso previo y por escrito de que no va a utilizar ni difundir los datos que afecten a la intimidad de las personas. Esa es una solución coherente con el hecho de que lo que vulnera la intimidad de las personas no es el acceso a los datos comprometidos, sino su difusión pública. Para establecer un límite al uso de esa información y para concretar responsabilidades ya existen el Código Civil y el Código Penal. Este sería un procedimiento alternativo al de la denegación preventiva, sin efectos secundarios tan graves, que permitirían conciliar ambos intereses, la investigación y la protección de la intimidad de las personas.

Cuando escribimos este artículo está elaborándose una Ley de Transparencia, Acceso a la Información Pública y Buen Gobierno, que pretende llenar un vacío clamoroso en nuestro ordenamiento jurídico. La propia Constitución estableció el principio de transparencia en la actuación de los poderes públicos, en asociación con otros principios básicos del sistema democrático, como son la eficacia, la seguridad jurídica y el principio de legalidad. Por ello, en el art. 105,b recogió de forma explícita el derecho de "acceso de los ciudadanos a los archivos y registros administrativos". Estamos convencidos, de que las leyes que regulan el acceso a los archivos públicos constituyen uno de los indicadores más fiables del grado de democracia alcanzado en un país. No haremos ahora el análisis de un anteproyecto que puede sufrir muchas variaciones hasta su aprobación definitiva, si llega a producirse, pero la lectura del borrador no invita al optimismo, y no conviene hacerse muchas ilusiones de que esta vaya a ser la llave que despeje y aclare el derecho de acceso a la documentación pública. Sólo apuntaremos un detalle: el texto preliminar refuerza los mecanismos sancionadores a los funcionarios que revelen datos o documentos protegidos, pero no dice nada sobre el incumplimiento, justamente, del deber de transparencia. No existe sanción prevista por un exceso de rigorismo, pero sí por negligencia en la custodia de la documentación.

Mientras tanto, hay soluciones que dependen de la Administración, tanto central como autonómica. Está en manos de la Dirección General de Bellas Artes y Bienes Culturales y de Archivos y Bibliotecas, responsable de los archivos históricos dependientes del Estado, dictar las instrucciones y reglas específicas que serán de aplicación en los archivos históricos, incluido el Archivo General de la Administración. Es de desear que, al menos en ese ámbito, se acabe con la suplantación de funciones, los abusos de ley, las actuaciones arbitrarias y los graves errores de procedimiento que hemos señalado como malas prácticas. Esperemos que se realice la disociación de datos cuando corresponda; que se establezca un procedimiento que dé seguridad jurídica para resolver los conflictos relativos al acceso a los archivos históricos; que se ponga en funcionamiento la Comisión Superior Calificadora de Documentos Administrativos y las Comisiones calificadoras específicas, en sus competencias relati- 
vas al régimen de acceso a la documentación de carácter histórico; que se establezcan unas normas claras de interpretación de las restricciones contempladas en las leyes; que se regulen y apliquen las excepciones a favor del acceso a datos expresamente protegidos cuando prime un interés científico o histórico relevante, etc.

Los historiadores no pedimos privilegios. Sólo exigimos que se nos reconozcan los derechos que asisten a cualquier ciudadano en sus relaciones con la Administración. A menudo se olvida que entre los principios de un Estado democrático se encuentra el de estar regido por el principio de transparencia, la sujeción a las normas de derecho, su orientación al servicio público y servir de garantía de los derechos de los ciudadanos. Los profesionales de los archivos también tienen derecho a reclamar normas claras, homogéneas e inequívocas para desarrollar su trabajo diario con seguridad.

Los historiadores contemporaneístas creemos que la investigación rigurosa es la única manera de salir con honor y justicia, gracias al conocimiento fehaciente de los hechos, de las crisis de memoria como la que atraviesa desde hace unos años nuestra sociedad. Para hacerlo, necesitamos que se garantice la libertad de acceso a la información de archivo, porque nuestra actividad sigue apoyándose en la máxima: quod non est in acta, non est in mundo. Cualquiera puede comprender, y no nos extenderemos sobre ello, las consecuencias que las restricciones a la investigación tienen sobre la calidad de la historiografía, sobre todo la que aborda temas relacionados con el pasado más próximo, y la ventaja que obtienen, al contrario, las interpretaciones y los análisis más disparatados, que no se apoyan en evidencias documentales sino que se benefician precisamente de su inaccesibilidad. 